\title{
Informing the Public How Party Communication Builds Opportunity Structures
}

Popa, Sebastian Adrian; Fazekas, Zoltán ; Braun, Daniela; Leidecker-Sandmann, MelanieMarita

Document Version

Accepted author manuscript

Published in:

Political Communication

DOI:

10.1080/10584609.2019.1666942

Publication date:

2020

License

Unspecified

Citation for published version (APA):

Popa, S. A., Fazekas, Z., Braun, D., \& Leidecker-Sandmann, M-M. (2020). Informing the Public: How Party Communication Builds Opportunity Structures. Political Communication, 37(3), 329-349.

https://doi.org/10.1080/10584609.2019.1666942

Link to publication in CBS Research Portal

\section{General rights}

Copyright and moral rights for the publications made accessible in the public portal are retained by the authors and/or other copyright owners and it is a condition of accessing publications that users recognise and abide by the legal requirements associated with these rights.

Take down policy

If you believe that this document breaches copyright please contact us (research.lib@cbs.dk) providing details, and we will remove access to the work immediately and investigate your claim. 


\section{Informing the Public: How Party Communication Builds Opportunity Structures}

\section{Sebastian Adrian Popa, Zoltán Fazekas, Daniela Braun, and Melanie-Marita Leidecker- Sandmann}

Journal article (Accepted manuscript*)

\section{Please cite this article as:}

Popa, S. A., Fazekas, Z., Braun, D., \& Leidecker-Sandmann, M-M. (20२०). Informing the Public: How Party Communication Builds Opportunity Structures. Political Communication, 3Х3), 329-349. https://doi.org/10.1080/10584609.2019.1666942

This is an Accepted Manuscript of an article published by Taylor \& Francis in Political Communication on ०८ OCT २०19, available online:

DOI: https://doi.org/10.1080/10584609.2019.1666942

* This version of the article has been accepted for publication and undergone full peer review but has not been through the copyediting, typesetting, pagination and proofreading process, which may lead to differences between this version and the publisher's final version AKA Version of Record. 


\title{
Informing the Public: How Party Communication Builds Opportunity Structures
}

\author{
Sebastian A. Popa \\ Newcastle University/ MZES, Mannheim \\ Sebastian.popa@ncl.ac.uk \\ Zoltán Fazekas
}

Department of International Economics, Government and Business, Copenhagen Business School zoltan.fazekas@gmail.com

Daniela Braun

LMU Munich/ MZES, Mannheim (External Fellow)

daniela.braun@gsi.uni-muenchen.de

Melanie-Marita Leidecker-Sandmann

Karlsruhe Institute of Technology (KIT)

leidecker-sandmann@kit.edu

\begin{abstract}
Pre-publication version, paper forthcoming in Political Communication.
Please cite published version: http://dx.doi.org/10.1080/10584609.2019.1666942.
\end{abstract}

Funding: Supported by the EUENGAGE project funded by the Horizon research and innovation programme under grant agreement No 649281 - EUENGAGE - H2020-EURO-2014-2015/H2020-EURO-SOCIETY2014. Press release data was collected in the context of a research grant to Silke Adam and Michaela Maier supported by the Swiss National Science Foundation (100017E-144592/1) and the German Science Foundation (MA 2244/5-1).

Acknowledgements: We are much indebted to our coders and research assistants: Shirin Tumenbaeva and Nora Kirkizh. We are also grateful for comments received on previous versions presented at the 7th Annual General Conference of the European Political Science Association (2017), "EU Politics: Institutions, Legislators, and Voters" workshop at the University of Oslo (2018), and the North-East Research Development Workshop (2019). For valuable feedback, we thank Pablo Barberá, Sara Hobolt, Yannis Theocharis, the editor, and three anonymous reviewers at the Political Communication. Materials to reproduce analysis reported in the paper can be found at: https://doi.org/10.7910/DVN/ZRMLCR 


\title{
Informing the Public: \\ How Party Communication Builds Opportunity Structures
}

\begin{abstract}
We argue that the attention parties devote to a topic contributes to expanding the opportunity structure to acquire information that party supporters have. We evaluate this proposition in a comparative manner by focusing on an elite-driven new topic, namely the Spitzenkandidaten system in European Parliament elections. We link candidate recognition survey data from 28 countries with over 175 party electoral programs, press releases, and Twitter communication before the 2014 European Parliament elections. Our results show that especially what parties emphasize or decide to talk about on Twitter contributes to what their supporters will know. As proposed, this is an indirect effect through a general contribution to the information environment in election campaigns. However, party communication portfolios should not discount traditional tools given that these can also contribute to the opportunity structures available to party supporters.
\end{abstract}

KEYWORDS: Political knowledge, Party communication, Spitzenkandidaten, European Parliament elections 
Are today's political parties successful in disseminating relevant information to their supporters? Answering this question is important for three main reasons. First, possessing knowledge about the political system and actors contributes to better political decisions and a higher quality of democratic representation. Second, a shared information base between parties and the public reduces disconnect and ensures that political competition at elite and voter level converge, overall cementing the role of parties in democratic societies. Third, provision of politically relevant information is regarded as one of the core functions of political parties, as they should help citizens in evaluating the complex and remote world of politics.

Theoretically, the opportunity structure from the ability-motivation-opportunity triad (Delli Carpini \& Keeter, 1996; Luskin, 1990) links supply side efforts with individual level knowledge. Political parties can contribute to the opportunity element defined as the "information to which one is exposed" (Luskin, 1990), potentially facilitating the acquisition of political knowledge for their supporters and, ultimately, for the general public (Zaller, 1992). We argue that parties can use various communication tools that serve as input for the opportunity structure and this expands the information (environment) available to their supporters, which then affects the amount of political information at the individual level. This argument builds on research regarding the capacity of parties to set the media agenda and subsequently influence public opinion (e.g. Hayes, 2008; Hopmann, Elmelund-Præstekær, Albæk, Vliegenthart, \& Vreese, 2012) and work on how the public's perception is linked to what parties say in their official communication (e.g. Adams, Ezrow, \& Somer-Topcu, 2011; P. Fernandez-Vazquez, 2014).

A major difficulty in these analyses is isolating the effect of elite communication during campaigns from the role of pre-existing views already held by citizens (Druckman \& Lupia, 2016). Furthermore, parties can adjust their focus on issues expected to be important for the public, amplifying confounding of effects. To overcome these limitations, we investigate how 
information about a new topic presented in the official party communication relates to citizens' awareness of the topic. Our test case is an important institutional development, namely the Spitzenkandidaten or lead candidate system. This is a topic which has not been emphasized before the 2014 elections to the European Parliament (EP) where political elites had a clear role in introducing and promoting it; moreover, the potential theoretical and practical implications of this development are far-reaching.

We contribute to the debate regarding the role of "traditional" communication tools of political parties, like electoral manifestos (Adams, Ezrow, \& Somer-Topcu, 2014; FernandezVazquez, 2014) and press releases (Harris et al., 2008; Hopman et al., 2012), in shaping the public agenda in an era when multiple communication tools are available to parties. Importantly, we extend these debates by exploring how social media communication, as a new tool, can facilitate information acquisition among party supporters. From a variety of social media platforms we analyze candidate Twitter communication because of its widespread, repeated and permanent use in political campaigns (e.g Grant, Moon, \& Grant, 2010; Gulati \& Williams, 2010; Larsson, 2015), and because of its potential to bypass traditional media or serve as input for it (e.g. Broersma \& Graham, 2013; Chadwick, 2013).

Our results based on communication from over 175 European political parties across three platforms (manifestos, press releases, and Twitter) indicate that what parties emphasize matters for knowledge acquisition of their supporters, with candidate Twitter communication playing a dominant role. Since parties employ all these different communication tools simultaneously, our approach indirectly contributes to evaluating which communication platforms are effective. Overall, while social media has often been regarded as having negative direct learning consequences, our findings are more optimistic in this regard. Finally, from a substantive point of view, although supply-side salience of the Spitzenkandidaten system was 
limited, low-cost communication efforts did contribute to knowledge about the system among supporters of parties that emphasized the topic more extensively.

\section{Party communication and the acquisition of political knowledge}

\section{The opportunity structure}

We investigate the extent to which parties can inform the public by focusing on a specific type of information, i.e. factual political knowledge defined as "factual knowledge about institutions and process of the government, current economic issues and social conditions, the major issues of the day, and stands of political leaders on those issues" (Delli Carpini \& Keeter, 1996, p. 1). As with any type of learning, understanding how individuals acquire this type of information is guided by the ability-motivation-opportunity triad (Delli Carpini \& Keeter, 1996; Luskin, 1990). Ability underlines the importance of cognitive skills in determining the ease with which individuals acquire new information. Motivation refers to the desire to learn and determines to what degree individuals seek information and how much attention they pay to it. While the ability of citizens is independent of party communication, we need to note that as a result of selective exposure and motivated reasoning (Brenes Peralta, Wojcieszak, Lelkes, \& de Vreese, 2017; Gaines, Kuklinski, Quirk, Peyton, \& Verkuilen, 2007; Levendusky, 2013; Taber \& Lodge, 2006) citizens are more motivated to seek and pay attention to information coming from their own party.

Previous research explaining levels of political knowledge has overwhelmingly focused on the two elements described above. However, the third, opportunity, is the most important avenue for connecting party communication and individual-level political knowledge, and hence the most suitable mechanism for theorizing party information effects. Opportunity to acquire information refers to more contextual factors that lie largely outside the individual's control (Luskin, 1990) and linkages between the public and elite communication are 
established through the changing opportunity structure for knowledge acquisition. Previous research has shown that by supplying more information during electoral campaigns the media expands the information environment available to citizens, hence increasing the opportunities to become informed and ultimately increasing the levels of political knowledge (Ferrín, Fraile, \& García-Albacete, 2019). Similarly, parties can also expand the information environment available to the public in relation to a given topic through their routine communication processes. By highlighting certain topics/issues in their official communication, parties increase the salience of that given topic/issue (Budge \& Farlie, 1983). These topics are then most likely to be picked up by the media and thus communicated to the public at large, and/or reach citizens via accidental and/or unintended exposure, increasing the likelihood that the public will encounter the information highlighted by parties (Bode, 2016; Shehata \& Strömbäck, 2018). The chances of a topic reaching the public are naturally higher for topics that are highly salient for the parties; that is, the chances of reaching the public are contingent on the emphasis which parties place on a topic. Nevertheless, given selective exposure and motivated reasoning, we would expect an increase in topic knowledge especially among the supporters of parties that pay substantial attention to the subject.

\section{How can parties provide information to the public?}

The potentially important role of parties in educating the public was most visible in the first two decades after World War II, "the 'golden age' of parties" (Janda \& Colman, 1998, p. 612). However, this role has been weakened due to the rise of TV broadcasting, with journalists actively seeking "ways to stamp their marks on political stories" (Blumler \& Kavanagh, 1999, p. 215). By the 1990s, the news time devoted to what politicians actually say decreased dramatically (Harrison, 1997; Blumler \& Kavanagh, 1999), with a trend towards shorter "text/sound-bites" of politicians in election coverage (Esser, 2008; Patterson, 1993). 
These developments represent a challenge for parties in their attempts to reach and inform their own supporters or the general public. Contributing to the opportunity structure available to supporters and the general public, party communication strategists can adopt various tools.

Press releases represent one traditional communication tool that parties or candidates can use to influence and inform their supporters. They are published frequently (sometimes on a daily basis) and are specifically geared towards the media and the general public (e.g. Grimmer, 2013; Maier, Bacherle, Adam, \& Leidecker-Sandmann, 2019). Due to limited resources and time pressure, journalists rely on easily accessible sources of information such as press releases. In sum, "political parties are quite successful in shaping the media agenda" (Hopmann et al., 2012). Therefore, press releases seem to be a good indicator for issues that are transmitted to the public and for the salience associated with these issues by the communicator.

Recent research has also looked at the impact on public opinion of official party communication through party manifestos (see Adams et al., 2014; Pablo Fernandez-Vazquez, 2014), or direct individual legislator communication (Broockman \& Butler, 2017) among others. In comparative party politics, the underlying idea of studies focusing on official party communication is that electoral manifestos generally reflect how salient political issues are for parties (Budge, Klingemann, Volkens, \& Bara, 2001). The content prioritized by parties in their electoral manifestos indicates how salient a topic is for them and this is reflected in what parties communicate via other avenues (Adams et al., 2011). One problem concerning party manifestos is that only a minor fraction of citizens read manifestos, although citizens are expected to pay attention to media coverage of these manifestos (Topf, 1994).

Aside from more traditional tools such as manifestos and press releases, parties also make use of other tools to communicate their message towards the mass media (Adam et al., 2017). Recent years have seen a move away from websites and blogs to various social media 
platforms, Twitter being one of the leading ones in political campaigns. Ease of use, potential to bypass mainstream media, and the limitless opportunities for personalized communication, have led to politicians strategically using social media to communicate their messages at a growing rate (Grant et al., 2010; Gulati \& Williams, 2010; Larsson, 2015).

Furthermore, candidate communication on social media not only bypasses traditional media in communicating with the public (Chadwick, 2013; Goldberg, 2010), but also serves as input for traditional media (Broersma \& Graham, 2013; Conway, Kenski, \& Wang, 2015). This is one of the main reasons for choosing Twitter over other social media platforms. As our goal is to investigate how the opportunity structure changes, we have selected the social media platform documented as having a greater influence on how political journalists work (that is, what sources they rely on) than for example Facebook (see Parmelee, 2014). Second, as we will be working with a newly established topic, Twitter has been shown to further feature as a source to detect emerging topics and supply background information for their coverage (see Jungherr, 2016). The less biased way in which Twitter displayed (at the time of the data collection) content is a further advantage on relying on Twitter rather than Facebook, which uses an algorithm that takes into account the preference of users for displaying content. Thus, while in the case of Twitter we are sure that a user following a politician is exposed to most of his or her communication, in the case of Facebook this is not the case. In this sense what political actors communicate over social media has become an important "news" source that not only has the capacity to influence the public agenda setting but also represents an important and legitimate source of information (Franco, Grimmer, \& Lee, 2016; Harder, Sevenans, \& Van Aelst, 2017; Van Dalen, Fazekas, Klemmensen, \& Hansen, 2015).

However, identifying the causal direction of links between party communication and public opinion or agenda is difficult. While some researchers have found little or no evidence of impact on public opinion of manifesto-based communication (Adams et al., 2014), others 
have shown that official party communication shapes the attitudes of party supporters (Fernandez-Vazquez, 2014). Furthermore, some evidence suggests that parties might adjust their official communication (i.e., electoral manifestos) in response to the attitudes of the public (Adams, Clark, Ezrow, \& Glasgow, 2004; Ezrow, de Vries, Steenbergen, \& Edwards, 2011; Popa \& Dumitrescu, 2015). Other studies focus on the question of the extent to which voters are knowledgeable, and how party behavior and communication-related features of the political system can account for these differences in knowledge (Fortunato, Stevenson, \& Vonnahme, 2016; Popa, 2015; Vegetti, Fazekas, \& Méder, 2016).

\section{Theoretical argument}

Our general expectation is that the attention political parties dedicate to a topic should signal to the public how important the issue is for the parties, which is in line with the salience theory of party competition (Budge \& Farlie, 1983). This leads us to expect that especially the supporters of parties that mention more often a particular topic have a greater chance of acquiring knowledge about that subject. This expectation is reinforced by the fact that citizens motivated by the need to seek out like minded information (Bennett \& Iyengar, 2008; Sunstein, 2001) are far more likely to pay attention to the message of their own party while dismissing information coming from the "others". In this regard, previous studies show that the way in which individuals search for and incorporate new information is clearly influenced by selective exposure and motivated reasoning (Brenes Peralta et al., 2017; Gaines et al., 2007; Levendusky, 2013; Taber \& Lodge, 2006).

Furthermore, social media allows for a large-scale transfer of information. If a given topic is covered more frequently on social media by politicians who have relatively many followers who pick up and spread their messages, the chances of accidental exposure to the topic increases exponentially (Bode, 2016; Shehata \& Strömbäck, 2018), reinforced also by 
potential attention given to the topic by media accounts. The chances of stumbling upon specific information posted by politicians is especially high among party supporters as they have been shown to be more likely to follow members of their own party (Barberá, 2015). Yet again, the possible impact of Twitter is not only given by its direct outreach as the tweets of politicians enjoy even greater outreach through indirect communication as they are recirculated by their followers to a secondary audience (Choi, 2015; Vaccari \& Valeriani, 2015). In addition, we can expect that those who avidly follow politicians on social media also have the potential to spread the messages they encounter online in their off-line social networks. This mechanism resembles the two-step flow of communication that was so important before the rise of mass media in facilitating the spread of information (Ernst, Engesser, Büchel, Blassnig, \& Esser, 2017, p. 1350; Katz \& Lazarsfeld, 1955), and is still capable nowadays of increasing the reach and strength of political messages (Aarøe \& Petersen, 2018).

The core of our argument is summarized as follows: parties' selective focus on political issues and topics is reflected in materials produced using various traditional (election manifestos and press releases) and new (Twitter) political communication tools. Selective focus translates into salience, operationalized through the amount of attention dedicated to topics. Higher salience increases citizens' chances of exposure (also incidental exposure) to the topic, which means the opportunity structure is more favorable for information acquisition. However, given the source (parties), selective exposure, and differences in motivation, this "party-influenced learning" should benefit those who identify with the communicating party compared to those who do not. Thus, our general hypothesis is: 
Opportunity hypothesis: individuals who support parties that devote more attention to a particular topic in their party communication are more likely to have factual knowledge about the topic compared to other individuals. ${ }^{1}$

\section{Test case of our study: the Spitzenkandidaten system}

To test this hypothesis, we make usage of the introduction of the Spitzenkandidaten (or lead candidates) for the 2014 EP elections, an EU-wide institutional development. This institutional innovation allows the different political groups in the EP the opportunity to nominate different Spitzenkandidaten, making parties the expected promoters of the Spitzenkandidaten system (Braun \& Popa, 2018). This was (theoretically) supposed to increase the prominence of European elections (Hobolt, 2014). This test case has several desirable properties for testing party communication influence on the opportunity structure.

First, this is not an instance of policy-specific knowledge mainly concerned with policy/issue stances (Barabas, Jerit, Pollock, \& Rainey, 2014), thus limiting potential biases by partisan predispositions (e.g. Prior, Sood, \& Khanna, 2015). Second, given the novelty of the system, it is unlikely that individuals chose the party they support based on their preferences for the lead candidates, limiting endogeneity issues from previous research on how parties influence public opinion. In addition, the low salience of the topic under consideration before the campaign ensures that pre-existing knowledge of it is low and the influence of parties on the public is clearer, without much prior contamination (Druckman \& Lupia, 2016).

Third, focusing on an electoral campaign period further ensures that politicians are especially active in communicating with the public and that citizens are also likelier to seek more information about what parties communicate (Beach, Hansen, \& Larsen, 2017; Larsson,

\footnotetext{
${ }^{1}$ By other individuals we mean supporters of parties that mention the topic less frequently, non-partisans and the partisans of those parties that did not mention the topic in their official communication.
} 
2015). Fourth, this is a case where the opportunity structure in the knowledge acquisition triad should be quite influential as citizens tend to lack motivation to learn about European affairs. This lack of motivation was also reflected by the relatively low proportion of citizens who were aware of the system (Gattermann, de Vreese, \& Van der Brug, 2016; Popa, Rohrschneider, \& Schmitt, 2016). However, awareness of the fact that candidates were nominated varied strongly among countries, being particularly high in the home countries of the Spitzenkandidaten (Hobolt, 2014; Schmitt, Hobolt, \& Popa, 2015).

To sum up, the EP election focus and the Spitzenkandidaten system as a knowledge component contributes to better identification of party information effects in a setting where informing citizens is a difficult task. First, parties' incentives to supply factual knowledge are lower than their incentives to provide policy-specific information, which is clearly illustrated in the case of the Spitzenkandidaten system by the low emphasis the parties accorded the topic in their manifestos (Braun \& Popa, 2018) as well as in their Facebook communication (Braun \& Schwarzbözl, 2018). Second, the mass media showed low interest in this novel topic (Maier et al., 2017) which can limit one of the main platforms for creating the opportunity structure to get informed, while also highlighting the importance of the opportunity structure created by political parties.

\section{Data and measures}

\section{Spitzenkandidaten knowledge}

In order to capture factual knowledge regarding the Spitzenkandidaten system, we use a nameparty recognition battery from the post-election wave of the 2014 European Election Study conducted simultaneously in 28 European countries (Schmitt et al., 2015). Respondents had to identify which EP party group or which national party supported the nomination of the three most important candidates: Jean-Claude Juncker (European People's Party), Martin Schulz 
(Socialists \& Democrats) and Guy Verhofstadt (Liberals and Allies Group). They were offered four response options including a fourth and incorrect option: "Socialists \& Democrat" (e.g. mentioning SPD in Germany), "European People's Party" (e.g. CDU/CSU), "Liberals and Allies Group" (e.g. FDP) and finally "The Greens" (e.g. Die Grünen) $)^{2}$ with a "Don’t know" option available. Our outcome variable is the proportion of correctly paired lead candidates out of the three correct answers (more information in Supplementary Information [SI] 1).

The recognition battery directly taps into political knowledge defined as "factual knowledge about institutions and process of the government, current economic issues and social conditions, the major issues of the day, and stands of political leaders on those issues" (Delli Carpini \& Keeter, 1996, p. 1). As this is a measure of "Surveillance Facts" (i.e. political knowledge about recent developments), it is ideal for capturing the effect of the opportunity structure on political knowledge (Barabas et al., 2014, p. 843). We should further note that the battery does not only reflect knowledge about the three specific candidates. The strong correlation between the three items forming our index (i.e. the average tetrachoric correlation between the items is 0.7 ) indicates that those who correctly respond to these items are also expected to know that Alexis Tsipras, Ska Keller and José Bové also took part in the race and so these respondents also have broader knowledge about the Spitzenkandidaten system (Popa et al., 2016).

It is worth noting that there is sizeable cross-country variation: $83 \%$ of the respondents in Luxembourg correctly linked Juncker to his party; however, this number is lowest in Estonia, with $4.3 \%$ of the respondents. For Schulz, the highest recognition is in Germany (69\%) and the lowest in the United Kingdom (3.63\%). Finally, Verhofstadt's recognition numbers were highest in Belgium (70\%) and lowest, again, in the United Kingdom (1.98\%). Luxembourg and

2 In countries where two or more parties were expected to join an EP group, the largest party was mentioned. In countries where there was no party supporting one of the four EP groups, only the name of the EP group was provided. 
Belgium registered the highest proportions for recognizing correctly all three candidates (around 21\%), with the lowest proportions in the United Kingdom and Ireland $(0.57 \%$ and $0.84 \%$ ). The proportion of people recognizing none of the candidates is highest in the Czech Republic (89\%), Lithuania (87\%), and Poland (86\%), and lowest in Luxembourg (12\%), Germany (23\%) and Belgium (23\%).

\section{Core predictors}

As the first platform within the traditional communication avenues, we use the EES 2014 Euromanifesto Study, which uses expert human coding and covers manifestos of the relevant parties competing in the 2014 EP elections (Schmitt, Braun, Popa, Mikhaylov, \& Dwinger, 2016). In order to reflect the conceptualization of the outcome variable, we rely on the coding scheme of the Euromanifesto Study which acknowledges that references or mentions to the Spitzenkandidaten system can take two forms. They can include mentions as a general issue, such as the Spitzenkandidaten system as a means to enhance legitimacy in the EU and/or mentions of all candidate names, including the three candidates who are not part of the battery measuring the outcome (Schmitt et al., 2016). We measure the emphasis a party places on the Spitzenkandidaten system as the proportion of the party manifesto pertaining to that topic. Out of 181 parties with Euromanifesto coding available, only 35 mention the candidates or the system and the highest share is $2.35 \%$ for the Czech Social Democratic Party. Hence, we dichotomize this measure as being 1 if any mention can be found in a party manifesto.

The second traditional communication platform concerns the use of press releases: 2658 press releases by 46 national parties and party coalitions from Austria, France, Germany, Greece, The Netherlands, Portugal, and the United Kingdom were collected as part of a larger research project ${ }^{3}$ and cover the campaign twelve weeks prior to the 2014 EP elections (see

\footnotetext{
3 "Political parties as politicizers of EU integration" by Silke Adam and Michaela Maier.
} 
more details in Adam et al., 2017). We build a thesaurus including the name of the lead candidates and varied forms of references to the positions in question (such as "President of the Commission" or "Lead candidate") based on detailed reading of the Euromanifestos (see Table 1). We then carry out text searches for all these terms of interest and code a press release mentioning the Spitzenkandidaten system if any of the terms are found. Our final predictor will be the proportion of press releases that contain Spitzenkandidaten mentions out of the total number of press releases sent out by a party.

Table 1: Spitzenkandidaten thesaurus

\begin{tabular}{ll}
\hline & List of terms \\
\hline Schulz & Martin Schulz; Schulz \\
Verhofstadt & Guy Verhofstadt; Verhofstadt \\
Tsipras & Alexis Tsipras; Tsipras \\
Keller & Ska Keller; Keller \\
Bové & José Bové; Bové \\
Juncker & Jean-Claude Juncker; Juncker \\
\hline Position & Head of EC; Head of European Commission; President of EC; President of European \\
& Commission; Candidate for EC; Candidate for European Commission; Top position in \\
& EC; Top candidate; Lead candidate; Joint candidate \\
\hline
\end{tabular}

Note: All terms have been translated into all languages following the official translations encountered in various communications from the three EU institutions.

In order to map candidate communication via social media, we use Twitter data collected as part of the European Election Study 2014 (for a more detailed discussion see Nulty et al., 2016; Theocharis et al., 2016). Our analysis covers $85 \%$ of the total MEP candidates who had a Twitter account and we analyze all candidate communication (original tweets, re-tweets, and replies) from the pre-election period ( 3 weeks) to capture campaign communication. We use the same thesaurus as before with translations in all languages of the European Union.

As previously, we want to identify whether any term from the thesaurus is present in a tweet. We are looking at Twitter with a 160-character limit where the text can be written on various devices, with abbreviations or potential spelling errors, especially in the case of names as they are not part of usual autocorrect dictionaries. Thus, rather than exact matches, we allow for some minor spelling errors (a 5\% margin) regarding the terms employed (formalized through a Jaro-Winkler distance, described and validated in SI 2). 
When calculating the party level measure, we choose to focus directly on the opportunity structure created, i.e. the party mentions weighted by their potential reach. This decision dovetails with our theoretical argument and it is possible because Twitter communication (and the platform) offers various statistics associated with the tweets. More precisely, while it would have been desirable, we do not have such measures for manifestos and press releases, so in this case we are measuring the difference in the attention of parties dedicate to the topic under consideration. This also means that any comparison between platforms should not be interpreted at face value, but we will return with more salience-related alternative measures of Twitter communication in the sections below, which might be better suited for comparison though they are more distant proxies of the opportunity structure.

For each tweet, we have information on the number of followers the candidate had at the moment of tweeting, which we sum across all candidates in one party. This stipulates the total reach throughout the campaign. We do the same for tweets mentioning the Spitzenkandidaten. Given the distribution of follower counts in both cases, we take the log of these and then create a measure that reflects the proportion of potential reach of the content of interest out of total reach throughout the campaign.

This approach is more complex than the ones for traditional platforms. It is needed because the opportunity structure created depends on the popularity of the account holder. Thus, our measure tackles the problem that a lead candidate mention from a candidate with 10 followers is not identical to a mention from an account with 300,000 followers. Furthermore, since we scale with total reach we do not regard these numbers in absolute terms because there is a large set of overlapping followers between tweets at different points in time as well as between different candidates (1), audiences and candidate numbers vary across countries (2), and we still want to keep features of the measure comparable to those used for traditional communication platforms (3). Detailed examples, validation and comparison between 
alternative measures are provided in SI 3. Furthermore, we will discuss alternative operationalizations later in the analysis section.

\section{Combining data sources and method}

For our analysis, we combine the individual-level data with the party-specific measures using respondents' party identification: we keep those respondents who named a party to which they feel close and those who said they did not feel close to any party, while all other do not know/do not want to tell answers were treated as missing. For EP election-specific parties, such as June List (Sweden) or People's Movement against the EU (Denmark), we used party vote in EP elections rather than party identification as a link.

At the party level, we were able to match 181 parties from the Euromanifestos, 178 from Twitter, and 46 from press releases, where data collection covered only a subset of seven European countries, with some sample size reduction because of parties not being in all three data sources. In this process, Malta was excluded overall, as no party had both manifesto and Twitter information. In all cases where individuals did not explicitly identify with any party, the party communication variables will take the theoretical minimum $(0)$. We offer a detailed description of the parties included and descriptive statistics in SI 1.

Our outcome is the proportion of correctly matched candidates, and thus we fit a series of hierarchical binomial regression models where individuals are nested within parties with which they identified and non-identifiers are regarded as a separate group. This approach also allows us to control for between individual differences and link party-level predictors to recognition scores. Finally, the partial pooling nature of these hierarchical models ensures that between party differences in effects are not overemphasized (as would be the case for nopooling models). We include controls for a number of factors that have been traditionally used to capture these aspects (i.e., education, knowledge about the EU, interest in politics, frequency 
of political discussion, and general news consumption). We further control for the exposure to the campaign, support for EU integration, and the age and gender of respondents. These control variables are listed in SI 4 with the exact wording from the 2014 EES Voter Study. At the party level, we include a dichotomous control for whether the party was a member of the European party group that backed any of the three lead candidates. As previous research has shown that the nationality of candidates needs to be considered when analyzing the effects of the Spitzenkandidaten system (Braun \& Popa, 2018; Schmitt, Hobolt, \& Popa, 2015), our model also includes country fixed effects.

\section{Party communication matters, especially on Twitter: main results}

First, we establish that there is a meaningful bivariate relationship between recognition and the predictors relating to opportunity structure taken independently (Figure 1). While the effect sizes are comparable in a statistical sense, ${ }^{4}$ there are differences in the operationalization and data availability, so direct comparisons are difficult. Nevertheless, we can see across platforms that more attention or higher reach is positively associated with differences in individual-level recognition, with comparable magnitudes, and more uncertainty regarding press releases. ${ }^{5}$ However, parties can use all these different communication platforms simultaneously, and so we extend these models below to jointly test these effects. Furthermore, the opportunity structure is only one part of the knowledge acquisition triad, and accordingly we account for other individual-level predictors in the next steps.

\footnotetext{
${ }^{4}$ After centering, continuous predictors are divided by two standard deviations as this allows a direct comparison of coefficients associated with continuous and dichotomous variables, and the size of the effect ranges from one standard deviation below the mean to one standard deviation above the mean (Gelman \& Hill, 2007).

${ }^{5}$ For some press releases digitalization relied on optical character recognition and thus we also ran a text search using the similarity-based approach employed for the Twitter platform. Allowing for potential mistakes, we have a slightly larger number of press releases with Spitzenkandidaten mentions. As reported in SI4, when using those values as predictors for the press release bivariate model the effect $(0.53)$ is statistically significant $(p=0.0275)$.
} 
We include relevant individual-level predictors of knowledge, a party-specific control, and country dummy variables. This specification serves as an important point of comparison for future models. Since the predictors included in these models are not central to analysis, we only highlight that they offer good face validity of our (mostly) individual level of recognition with results in line with previous research: more educated, interested and engaged individuals who also know in general about the EP have higher recognition scores (see Table 2).

Figure 1: Party communication on three platforms and Spitzenkandidaten recognition

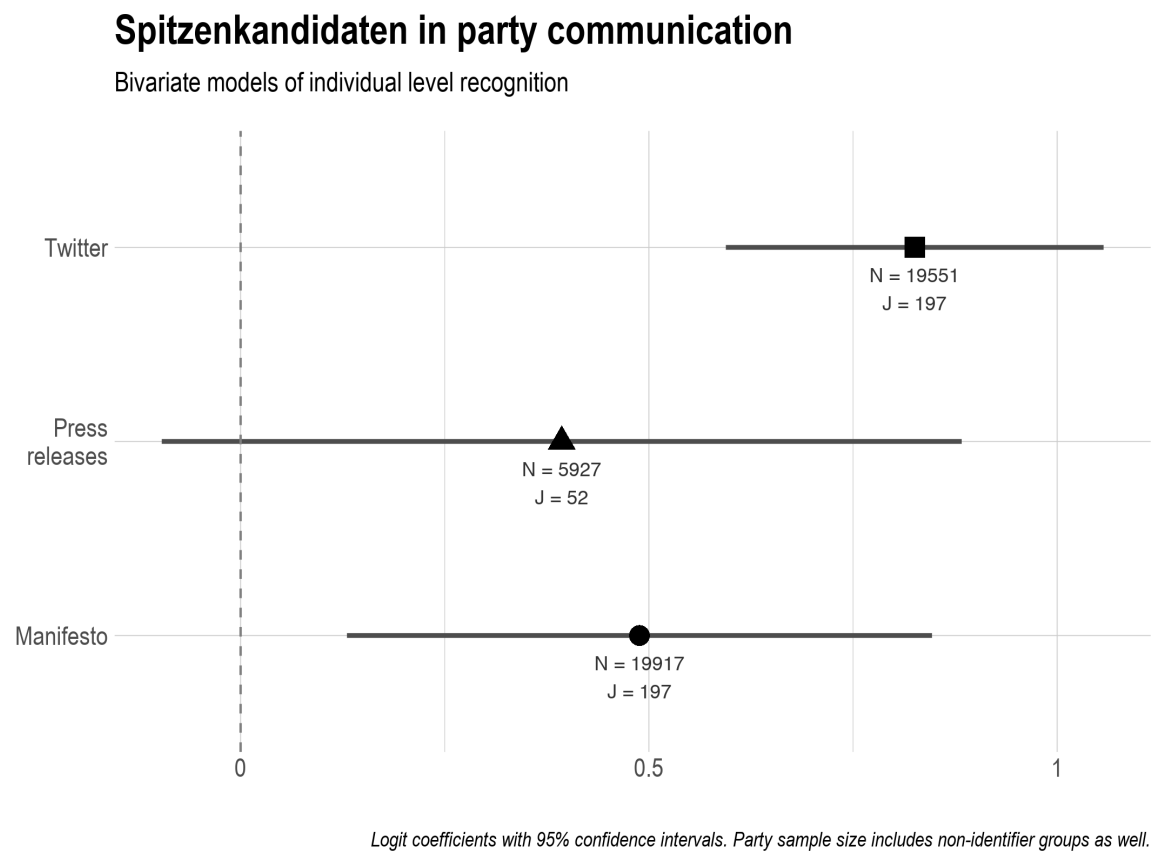

We find consistent evidence that the opportunity structure created through Twitter communication is positively associated with recognition, and attention in manifestos also contributes to the opportunity structure in a way that it can foster better candidate recognition. However, when we account for joint use and assess them together, we find that social media reach is more important. 
Table 2: Main results, party communication and Spitzenkandidaten recognition

\begin{tabular}{|c|c|c|c|c|c|c|c|}
\hline & $\begin{array}{l}\text { Baseline } \\
\text { (all) }\end{array}$ & $\begin{array}{c}\text { Twitter reach } \\
\text { (all) }\end{array}$ & $\begin{array}{c}\text { Manifesto mentions } \\
\text { (all) }\end{array}$ & $\begin{array}{l}\text { Both } \\
\text { (all) }\end{array}$ & $\begin{array}{c}\text { Baseline } \\
\text { (sub) }\end{array}$ & $\begin{array}{c}\text { Press release } \\
\text { salience (sub) }\end{array}$ & $\begin{array}{l}\text { All three } \\
\text { (sub) }\end{array}$ \\
\hline Intercept & $\mathbf{- 0 . 7 8}(0.16)$ & $\mathbf{- 0 . 7 8}(0.14)$ & $\mathbf{- 0 . 8 5}(0.15)$ & $\mathbf{- 0 . 8 2}(0.14)$ & $-\mathbf{0 . 8 8}(0.14)$ & $\mathbf{- 0 . 8 4}(0.14)$ & $\mathbf{- 0 . 8 6}(0.11)$ \\
\hline Sex $($ Female $=1)$ & $\mathbf{- 0 . 4 1}(0.03)$ & $\mathbf{- 0 . 4 1}(0.03)$ & $\mathbf{- 0 . 4 1}(0.03)$ & $\mathbf{- 0 . 4 1}(0.03)$ & $\mathbf{- 0 . 4 1}(0.04)$ & $\mathbf{- 0 . 4 1}(0.04)$ & $\mathbf{- 0 . 4 1}(0.04)$ \\
\hline Age & $\mathbf{0 . 3 3}(0.03)$ & $0.33(0.03)$ & $\mathbf{0 . 3 3}(0.03)$ & $\mathbf{0 . 3 3}(0.03)$ & $0.38(0.04)$ & $0.38(0.04)$ & $\mathbf{0 . 3 8}(0.04)$ \\
\hline Secondary education & $0.24(0.04)$ & $0.24(0.04)$ & $0.24(0.04)$ & $\mathbf{0 . 2 4}(0.04)$ & $0.22(0.05)$ & $0.22(0.05)$ & $\mathbf{0 . 2 2}(0.05)$ \\
\hline Tertiary education & $\mathbf{0 . 4 2}(0.04)$ & $\mathbf{0 . 4 2}(0.04)$ & $\mathbf{0 . 4 2}(0.04)$ & $\mathbf{0 . 4 2}(0.04)$ & $\mathbf{0 . 4 1}(0.06)$ & $\mathbf{0 . 4 2}(0.06)$ & $\mathbf{0 . 4 2}(0.06)$ \\
\hline EU knowledge & $0.35(0.03)$ & $\mathbf{0 . 3 5}(0.03)$ & $\mathbf{0 . 3 5}(0.03)$ & $\mathbf{0 . 3 5}(0.03)$ & $\mathbf{0 . 3 7}(0.05)$ & $\mathbf{0 . 3 7}(0.05)$ & $\mathbf{0 . 3 8}(0.05)$ \\
\hline Interest in politics & $\mathbf{0 . 5 7}(0.03)$ & $\mathbf{0 . 5 7}(0.03)$ & $\mathbf{0 . 5 7}(0.03)$ & $\mathbf{0 . 5 7}(0.03)$ & $\mathbf{0 . 5 1}(0.05)$ & $\mathbf{0 . 5 1}(0.05)$ & $\mathbf{0 . 5 1}(0.05)$ \\
\hline Campaign exposure & $\mathbf{0 . 1 3}(0.03)$ & $\mathbf{0 . 1 3}(0.03)$ & $\mathbf{0 . 1 3}(0.03)$ & $\mathbf{0 . 1 3}(0.03)$ & $\mathbf{0 . 3 0}(0.05)$ & $\mathbf{0 . 3 0}(0.05)$ & $\mathbf{0 . 3 0}(0.05)$ \\
\hline Political discussion & $0.29(0.03)$ & $\mathbf{0 . 2 9}(0.03)$ & $\mathbf{0 . 2 9}(0.03)$ & $\mathbf{0 . 2 9}(0.03)$ & $\mathbf{0 . 2 5}(0.05)$ & $0.25(0.05)$ & $\mathbf{0 . 2 5}(0.05)$ \\
\hline EU position & $\mathbf{0 . 2 0}(0.03)$ & $\mathbf{0 . 2 0}(0.03)$ & $\mathbf{0 . 2 0}(0.03)$ & $\mathbf{0 . 2 0}(0.03)$ & $\mathbf{0 . 2 2}(0.04)$ & $\mathbf{0 . 2 2}(0.04)$ & $\mathbf{0 . 2 2}(0.04)$ \\
\hline News consumption & $0.42(0.03)$ & $\mathbf{0 . 4 2}(0.03)$ & $\mathbf{0 . 4 2}(0.03)$ & $\mathbf{0 . 4 2}(0.03)$ & $\mathbf{0 . 4 0}(0.05)$ & $\mathbf{0 . 4 0}(0.05)$ & $\mathbf{0 . 4 0}(0.05)$ \\
\hline Party of lead candidate & $\mathbf{0 . 3 6}(0.06)$ & $\mathbf{0 . 1 8}(0.06)$ & $\mathbf{0 . 3 3}(0.06)$ & $\mathbf{0 . 1 8}(0.06)$ & $\mathbf{0 . 3 0}(0.10)$ & $0.23(0.11)$ & $0.06(0.09)$ \\
\hline Twitter reach & & $\mathbf{0 . 4 2}(0.06)$ & & $\mathbf{0 . 4 0}(0.07)$ & & & $\mathbf{0 . 2 1}(0.07)$ \\
\hline Manifesto mentions & & & $\mathbf{0 . 2 4}(0.09)$ & $0.13(0.09)$ & & & $\mathbf{0 . 2 8}(0.09)$ \\
\hline Press release mentions & & & & & & $0.16(0.10)$ & $0.10(0.08)$ \\
\hline$\overline{\mathrm{AIC}}$ & 31813.26 & 31776.67 & 31808.82 & 31776.26 & 10985.30 & 10985.00 & 10968.54 \\
\hline $\mathrm{BIC}$ & 32119.41 & 32090.67 & 32122.82 & 32098.11 & 11110.69 & 11116.98 & 11113.72 \\
\hline $\mathrm{N}$ & 18957 & 18957 & 18957 & 18957 & 5427 & 5427 & 5427 \\
\hline Parties & 176 & 176 & 176 & 176 & 43 & 43 & 43 \\
\hline (Variance) Parties & 0.12 & 0.08 & 0.11 & 0.08 & 0.07 & 0.06 & 0.02 \\
\hline
\end{tabular}

Notes: (Restricted) Maximum Likelihood estimates of logit coefficients with standard errors in parentheses. Entries in bold are statistically significant at $\mathrm{p}<0.05$. Country dummy variables included but omitted from the output (Intercept = Austria). Likelihood ratio tests have been carried out: both Twitter reach and Manifesto salience models fit the data significantly better than the Baseline model (valid for subsample as well), and the full sample model with both included fits better than Baseline and Manifesto only, but not better than Twitter reach. Press release salience model does not fit better than the Baseline. The results for Press release salience are not sensitive to a dichotomous (as for Manifestos) measure of salience. 
Whilst more attention to the Spitzenkandidaten system in press releases has a positive effect on recognition, this effect is not statistically significant. ${ }^{6}$ Our results in the last column of Table 2 suggest that manifesto and Twitter communications are systematically related to recognition, even within this smaller subset of parties and countries. One related (modelling) consideration is how much the communication content correlates across platforms. In this regard, our results are not influenced by multicollinearity in the statistical sense: Twitter and manifesto communication correlation is 0.26 (full sample) and 0.42 (press release subsample), and the press release correlations are 0.20 (with Twitter) and 0.28 (with manifestos). Beyond the statistical perspective, this indicates that attention and outreach for this topic is somewhat interrelated across platforms, but each platform has unique characteristics, likely because the different intended audiences and greater heterogeneity of candidate Twitter communication.

Figure 2: Generally low recognition, but higher with better opportunity structure

a. Twitter reach

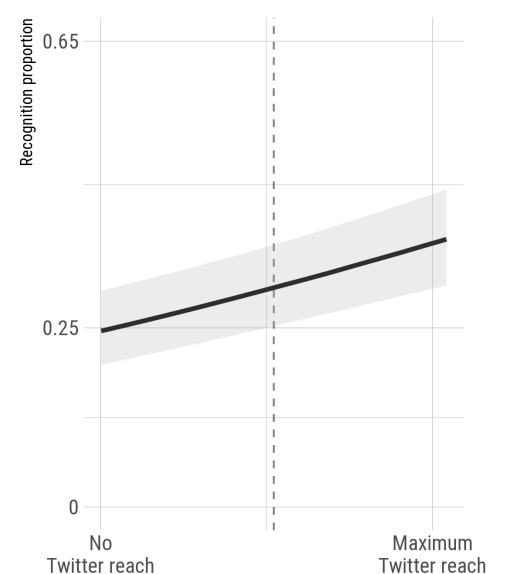

b. Euromanifesto mentions

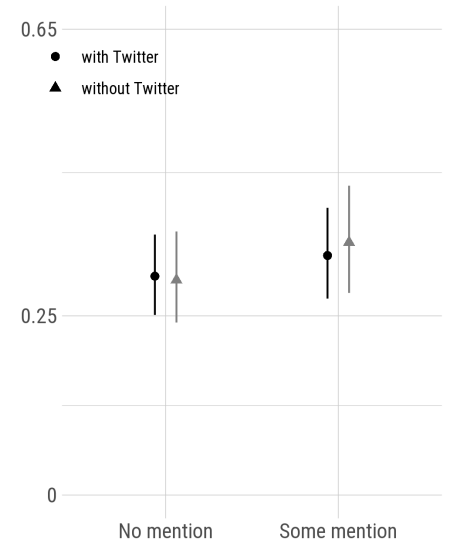

c. Press release mentions

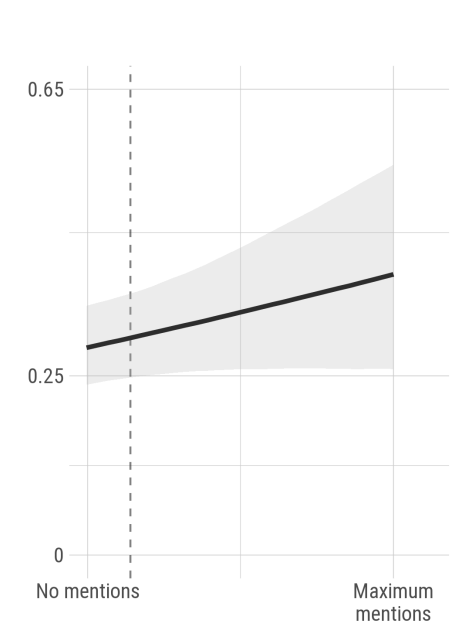

Note: Example predicted values calculated for average-aged Austrian man with lower than secondary education, no exposure to the campaign,
with average discussion frequency, news consumption and EU position. He is not a supporter of a party being behind a lead candidate. For Twitter reach, party manifesto salience is fixed at 0 . For manifesto salience with Twitter control (model: Both), Twitter reach fixed at sample mean.
Party-specific random effects collapsed (discarded), as hypothetical example. Shaded area and line ranges for $95 \%$ confidence intervals.

${ }^{6}$ As already mentioned and reported in SI4, when we use similarity-based search for press releases the effect in Press release salience model is statistically significant $(0.22, p=0.033)$. However, our findings from the final model are unchanged regarding press release salience $(0.11, \mathrm{p}=0.157)$. 
Figure 2 summarizes our results and shows that there is generally a low recognition proportion (also given the additional predictor values used in the example), but supporters of parties that designate attention to the topic are better at recognizing at least one out of the three candidates. Accordingly, our results indicate that citizens have scarce factual knowledge about a novel institutional feature, but party communication, especially through the opportunity structure created via social media, can ensure at least some knowledge about this institutional system. In the next section, we further investigate the robustness of our findings focusing on opportunity structure created through Twitter.

\section{Sensitivity checks: detailed look at the opportunity structure}

Not a simple partisanship effect

Using a varying intercept model with no predictors we generated the predicted average recognition proportions for all groups in our data. Because we fit the model to data containing both partisans and non-partisans where non-partisans in each country are treated as separate, we use these predicted values to assess whether we are looking at a partisanship effect or whether specific party communication indeed matters.

The average recognition across the 27 non-partisan groups is 0.122 , indicating very low recognition among those who do not identify with a party. Those groups that are identifiers but where the parties they identify with had no Twitter reach relevant for lead candidate content (44 groups) have an average recognition of 0.126 ( 0.183 for no manifesto mentions, 118 parties). The comparison between non-partisans and partisans with no relevant party communication suggests that differences in recognition due to uninformative partisanship are very small. Conversely, the groups where there is at least some relevant Twitter reach (105), the average recognition is 0.222 ( 0.232 for Euromanifesto, 31 parties $)$, indicating much larger differences. Similarly, we fit our model with all predictors on a subsample including partisans 
only (Figure 3, first entry), and we see that the results are unchanged regarding our Twitter reach conclusions.

\section{Not a general EU knowledge effect}

Second, we tackle the question of whether we are looking at some overarching EU-related contribution. This can be considered as a placebo test and we fit the same model to the data where our outcome is general EU knowledge rather than recognition, and we find no statistically or substantively significant effect of the Spitzenkandidaten-relevant opportunity structure (second entry in Figure 3). The linkages and opportunity structures we measure are thus specific and this strengthens our confidence in our measurements and substantive findings.

Figure 3: Summary of robustness and placebo test results

\section{Spitzenkandidaten in party communication}

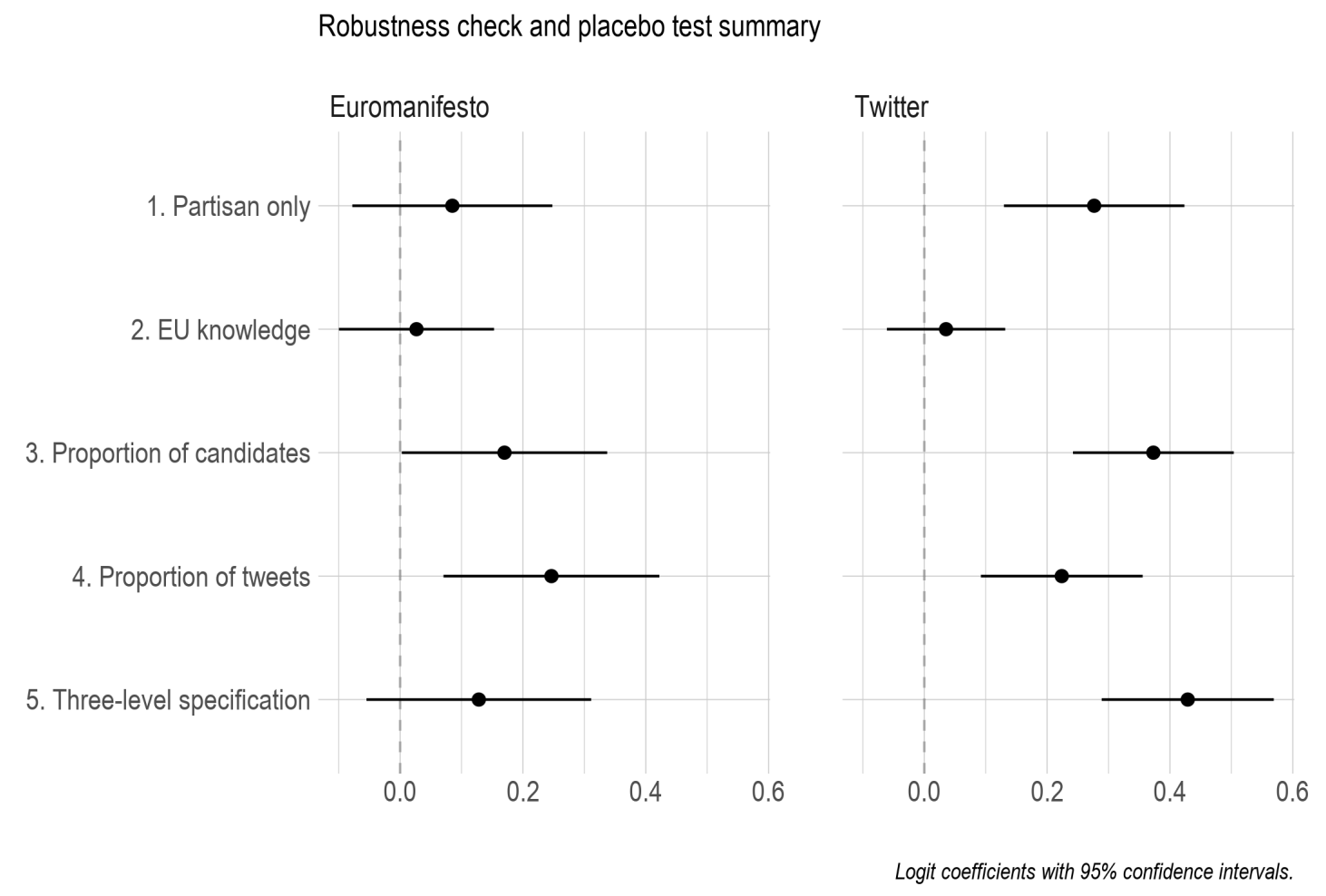




\section{Social media effects are not dependent measure choice or specification}

We made a deliberate choice to focus on a measure of Twitter communication that is closer to the opportunity structure (follower count-based). However, this also limits possible comparisons between platforms, granting some potential advantage to the social media platform results. Figure 3 also displays results from our model including all predictors with two alternative measures of the Twitter communication: proportion of candidates out of total candidates on Twitter mentioning the system/candidates and proportion of tweets mentioning the system/candidates out of the total tweets from the campaign, for each party. These are closer in principle to the manifesto measure used as a comparison. There is minor variation in the effect size for the proportion of tweets measurement; however, substantively and in terms of statistical significance our results are robust.

With the aim of keeping a similar specification for the models on the subsample where press release data was available, we decided to use country dummies. However, if our only focus is on the case where we cover 27 countries, we can alternatively fit a three-level hierarchical model (using our original Twitter reach measure), adding countries as the highest level of grouping. As in the previous cases, our checks indicate that the Twitter-related findings are robust with respect to this otherwise preferred specification choice.

\section{Opportunity structure as indirect source of factual knowledge}

We highlight here that Twitter-related party communication differences do not act through potentially direct exposure. Younger citizens are regarded as heavier social media users, hence if this effect would go through some sort of a potential for direct exposure, we would expect the party communication effect to be stronger for this group of people. Keeping the specification from our main model on the full sample size, we fit two models where the only change is related to using an age-group dichotomy: 35 and below in the first case and 25 and 
below for the second case, compared to older citizens. This effect is let to vary across party group (including no identification) and the age-group slope is a function of the Twitter reach measure.

Figure 4: No differences conditional on age-group

\section{Conditional effect of Twitter reach on age}
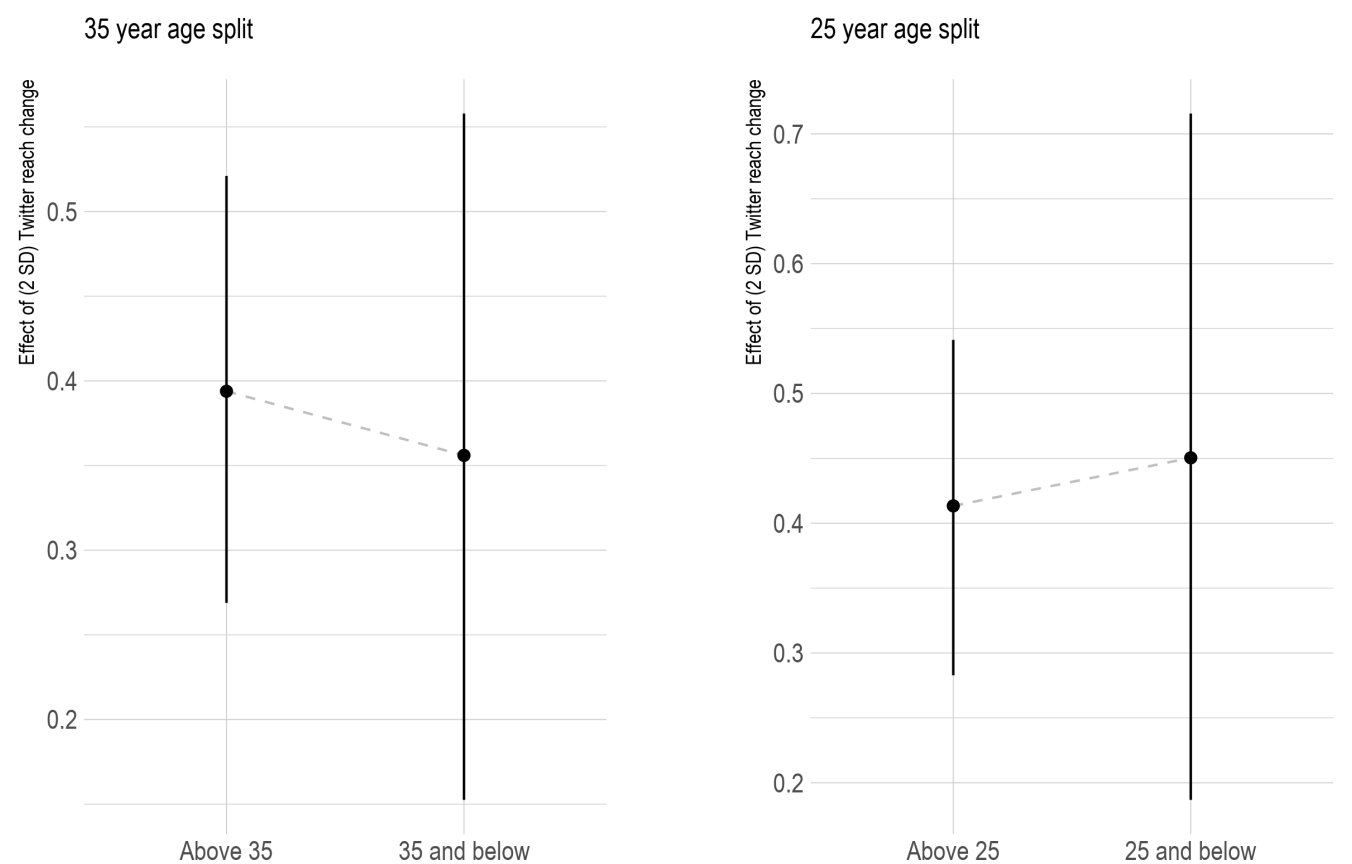

We find no evidence for any difference in terms of Twitter reach effect size across agegroups (see Figure 4). While a rough proxy for potential exposure as younger citizens might use social media more often but not for politics, this result indicates that party communication, even on social media, has a more general contribution to the opportunity structure. All detailed results from this section are reported in SI 4, where we also report results from a jackknife approach excluding one country and re-fit the models and an alternative Twitter outreach measure that is scaled by party supporter size. These additional tests indicate that all our substantive results are robust to various specifications and operationalization choices. 


\section{Conclusions}

We set out to answer whether today's political parties can inform their supporters by providing objective political knowledge and focused on the novel, low-salience institutional feature of Spitzenkandidaten in a comparative perspective. Generally, our answer is yes and in terms of opportunity structure building, novel communication platforms such as Twitter emerge as potentially important for the study of political knowledge acquisition. At the same time, we find that the role of manifestos in this regard is mixed, while (possibly due to the smaller sample) we do not detect a clear effect in the case of press releases.

These results are informative for the debate regarding the potential of official party communication (especially manifestos) to shape public opinion. In a cross-sectional, betweenindividual setting we find some evidence that party manifestos play a role in shaping what party supporters know about a topic. However, we see that a more direct measurement of an opportunity structure and thus informational context (rather than salience in communication by the supply side) is a more promising avenue for linking supply to demand in the study of political knowledge or electoral behavior. This echoes findings by Adams et al. (2014) where a broader measure of party position based on elite surveys fared better in explaining shifts in public opinion. This does not mean that we should dismiss traditional communication channels: their effects point to a positive impact, but this comes with more uncertainty. These differences are not surprising and are related to what these communication platforms can achieve: manifestos are a single-shot document early in the campaign that are intended to offer a comprehensive policy profile of the parties, whereas press releases are aimed directly at the media, and hence are potentially more dependent on media selection preferences.

We show that what parties emphasize or decide to talk about on social media matters for what their supporters and, by extension, the public end up knowing. We have also shown that both for Twitter and manifesto communication, we only find topic-specific, not general 
knowledge-related differences and these go beyond a simple partisan versus non-partisan dichotomy. However, the results also indicate that while substantively important, the potential party communication influence is at best suitable for increasing the minimum levels of factual knowledge, rather than for creating expert party sympathizers. Furthermore, party communication contributes to a broader opportunity structure regarding the topic, and social media reach is unlikely, based on our measures, to act directly through potential exposure.

However, the cross-sectional nature of the data presented here makes causal claims especially on the direction of influences - quite difficult and this is a key limitation. The publicto-elite direction implies that the salience of the Spitzenkandidaten system in a campaign is a result of following the (supposed) interest towards the topic among the public or the party's own supporters. While our empirical strategy cannot directly dismiss this direction, we regard this mechanism as unlikely given the novelty of the topic, its low salience, and the fact that the Spitzenkandidaten system is an elite-driven project. Accordingly, citizens had at best little substantive knowledge about this topic before the campaign as they had neither the motivation nor the opportunity to learn about it.

Most importantly, we need to emphasize that we rely on the previously tested assumption that the link between parties and their supporters is driven by selective exposure and motivated reasoning (Brenes Peralta et al., 2017; Gaines et al., 2007; Levendusky, 2013; Taber \& Lodge, 2006), but we do not test it explicitly in our cross-sectional analysis. Similarly, we do not test how information from the communication platforms reaches citizens, directly or indirectly. Based on existing research we can only assume that topics which are emphasized by parties are likely to reach citizen via accidental, unintended exposure, and through the media coverage (Bode, 2016; Shehata \& Strömbäck, 2018). These limitations need to be considered as a next step in understanding how what parties and candidates say reaches their supporters or the general public (Geers, Bos, \& de Vreese, 2017; Lecheler \& de Vreese, 2017). Furthermore, 
for our test case, negative information or negative campaigning was not at play, but social media communication might attract more interaction and negativity compared to the two other party sources (especially manifestos). This is important as it has been shown that negative information might cut through this protective shield of selective exposure more easily (Donsbach, 1991).

Finally, we focused only on Twitter, but platforms such as Facebook should be considered as well, especially because the popularity of these social media platforms might vary across countries, or even specific party supporters. With these limitations and potential future avenues in mind, our results consistently indicate that what parties talk about matters for what voters know and this opportunity structure for knowledge acquisition is likely influenced by newer communication tools such as Twitter that are playing an increasingly more important role in election campaigns.

\section{References}

Aarøe, L., \& Petersen, M. B. (2018). Cognitive Biases and Communication Strength in Social Networks: The Case of Episodic Frames. British Journal of Political Science, 1-21. https://doi.org/10.1017/s0007123418000273

Adam, S., Antl-Wittenberg, E.-M., Eugster, B., Leidecker-Sandmann, M., Maier, M., \& Schmidt, F. (2017). Strategies of pro-European parties in the face of a Eurosceptic challenge. European Union Politics, 18(2), 260-282. https://doi.org/10.1177/1465116516661248

Adams, J., Clark, M., Ezrow, L., \& Glasgow, G. (2004). Understanding Change and Stability in Party Ideologies: Do Parties Respond to Public Opinion or to Past Election Results? British Journal of Political Science, 34(4), 589-610. https://doi.org/10.1017/S0007123404000201 
Adams, J., Ezrow, L., \& Somer-Topcu, Z. (2011). Is Anybody Listening? Evidence That Voters Do Not Respond to European Parties’ Policy Statements During Elections. American Journal of Political Science, 55(2), 370-382. https://doi.org/10.1111/j.15405907.2010.00489.x

Adams, J., Ezrow, L., \& Somer-Topcu, Z. (2014). Do Voters Respond to Party Manifestos or to a Wider Information Environment? An Analysis of Mass-Elite Linkages on European Integration. American Journal of Political Science, 58(4), 967-978.

https://doi.org/10.1111/ajps.12115

Barabas, J., Jerit, J., Pollock, W., \& Rainey, C. (2014). The Question(s) of Political Knowledge. American Political Science Review, 108(4), 840-855. https://doi.org/10.1017/S0003055414000392

Barberá, P. (2015). Birds of the Same Feather Tweet Together: Bayesian Ideal Point Estimation Using Twitter Data. Political Analysis, 23(1), 76-91.

Beach, D., Hansen, K. M., \& Larsen, M. V. (2017). How Campaigns Enhance European Issues Voting During European Parliament Elections. Political Science Research and Methods, 1-18. https://doi.org/10.1017/psrm.2017.6

Bennett, L. W., \& Iyengar, S. (2008). A New Era of Minimal Effects? The Changing Foundations of Political Communication. Journal of Communication, 58(4), 707-731. Blumler, J. G., \& Kavanagh, D. (1999). The Third Age in Political Communication: Influences and Features. Political Communication, 16, 209-230.

Bode, L. (2016). Political News in the News Feed: Learning Politics from Social Media. Mass Communication and Society, 19(1), 24-48. https://doi.org/10.1080/15205436.2015.1045149

Braun, D., \& Popa, S. A. (2018). This time it was different? The salience of the Spitzenkandidaten system among European parties. West European Politics, 41(5), 
1125-1145. https://doi.org/10.1080/01402382.2017.1419003

Braun, D., \& Schwarzbözl, T. (2018). Put in the spotlight or largely ignored? Emphasis on the Spitzenkandidaten by political parties in their online campaigns for European elections. Journal of European Public Policy, 1-18. https://doi.org/10.1080/13501763.2018.1454493

Brenes Peralta, C., Wojcieszak, M., Lelkes, Y., \& de Vreese, C. (2017). Selective Exposure to Balanced Content and Evidence Type: The Case of Issue and Non-Issue Publics About Climate Change and Health Care. Journalism \& Mass Communication Quarterly, 94(3), 833-861. https://doi.org/10.1177/1077699016654681

Broersma, M., \& Graham, T. (2013). Twitter as a News Soruce. Journalism Practice, 7(4), 446-464. https://doi.org/10.1080/17512786.2013.802481

Broockman, D. E., \& Butler, D. M. (2017). The Causal Effects of Elite Position-Taking on Voter Attitudes: Field Experiments with Elite Communication. American Journal of Political Science, 61(1), 208-221. https://doi.org/10.1111/ajps.12243

Budge, I., \& Farlie, D. J. (1983). Explaining and Predicting Elections: Issue Effects and Party Strategies in Twenty-three Democracies. London: George Allen \& Unwin.

Budge, I., Klingemann, H.-D., Volkens, A., \& Bara, J. (2001). Mapping Policy Preferences, Estimates for Parties, Governments and Electors 1945-1998. Oxford: Oxford University Press.

Chadwick, A. (2013). The hybrid media system: Politics and power. New York: Oxford University Press.

Choi, S. (2015). The Two-Step Flow of Communication in Twitter-Based Public Forums. Social Science Computer Review, 33(6), 696-711. https://doi.org/10.1177/0894439314556599

Conway, B., Kenski, K., \& Wang, D. (2015). The rise of Twitter in the political campaign: 
Searching for intermedia agenda-setting effects in the presidential primary. Journal of Computer-Mediated Communication, 20(4), 363-380.

Delli Carpini, M. X., \& Keeter, S. (1996). What Americans Know about Politics and Why It Matters. New Haven: Yale University Press.

Donsbach, W. (1991). Exposure to Political Content in Newspapers: The Impact of Cognitive Dissonance on Readers' Selectivity. European Journal of Communication, 6(2), 155186. https://doi.org/10.1177/0267323191006002003

Druckman, J. N., \& Lupia, A. (2016). Preference Change in Competitive Political Environments. Annual Review of Political Science, 19(1), 13-31. https://doi.org/10.1146/annurev-polisci-020614-095051

Ernst, N., Engesser, S., Büchel, F., Blassnig, S., \& Esser, F. (2017). Extreme parties and populism: an analysis of Facebook and Twitter across six countries. Information, Communication \& Society, 20(9), 1347-1364. https://doi.org/10.1080/1369118X.2017.1329333

Esser, F. (2008). Dimensions of Political News Cultures: Sound Bite and Image Bite News in France, Germany, Great Britain, and the United States. The International Journal of Press/Politics, 13(4), 401-428. https://doi.org/10.1177/1940161208323691

Ezrow, L., De Vries, C., Steenbergen, M., \& Edwards, E. (2011). Mean voter representation and partisan constituency representation: Do parties respond to the mean voter position or to their supporters? Party Politics, 17(3), 275-301.

https://doi.org/10.1177/1354068810372100

Fernandez-Vazquez, P. (2014). And Yet It Moves: The Effect of Election Platforms on Party Policy Images. Comparative Political Studies, 47(14), 1919-1944. https://doi.org/10.1177/0010414013516067

Ferrín, M., Fraile, M., \& García-Albacete, G. M. (2019). Who Learns in Information Rich 
Contexts? The Informative Effects of the 2015 Spanish Electoral Campaign. https://doi.org/10.1177/1940161219832455

Fortunato, D., Stevenson, R. T., \& Vonnahme, G. (2016). Context and Political Knowledge: Explaining Cross-National Variation in Partisan Left-Right Knowledge. The Journal of Politics, 78(4), 1211-1228. https://doi.org/10.1086/686689

Franco, A., Grimmer, J., \& Lee, M. (2016). Changing the Subject to Build an Audience: How Elected Officials Affect Constituent Communication.

Gaines, B. J., Kuklinski, J. H., Quirk, P. J., Peyton, B., \& Verkuilen, J. (2007). Same facts, different interpretations: Partisan motivation and opinion on Iraq. Journal of Politics, 69(4), 957-974.

Gattermann, K., De Vreese, C., \& Van der Brug, W. (2016). Evaluations of the Spitzenkandidaten: The Role of Information and News Exposure in Citizens' Preference Formation. Politics and Governance, 4(1), 37-54. https://doi.org/10.17645/pag.v4i1.460

Geers, S., Bos, L., \& De Vreese, C. H. (2017). Informed Switchers? How the impact of election news exposure on vote change depends on political information efficacy. International Journal of Communication, 11, 1857-1878. https://doi.org/10.1097/HCO.0000000000000558

Gelman, A., \& Hill, J. (2007). Data analysis using regression and multilevelhierarchical models. New York: Cambridge University Press.

Goldberg, G. (2010). Rethinking the Public/Virtual Sphere: The Problem with Participation. New Media \& Society, 13(5), 739-754. https://doi.org/10.1177/1461444810379862

Grant, W. J., Moon, B., \& Grant, J. B. (2010). Digital dialogue? Australian politicians' use of the social network tool Twitter. Australian Journal of Political Science, 45(4), 579-604. Grimmer, J. (2013). Representational Style in Congress: What Legislators Say and Why It Matters. Cambridge University Press. 
Gulati, J., \& Williams, C. B. (2010). Communicating with Constituents in 140 Characters or Less: Twitter and the Diffusion of Technology Innovation in the United States Congress. SSRN. https://doi.org/10.2139/ssrn.1628247

Harder, R. A., Sevenans, J., \& Van Aelst, P. (2017). Intermedia Agenda Setting in the Social Media Age: How Traditional Players Dominate the News Agenda in Election Times. The International Journal of Press/Politics, 194016121770496. https://doi.org/10.1177/1940161217704969

Harrison, M. (1997). Politics on the Air. In The British General Election of 1997 (pp. 133155). London: Palgrave Macmillan UK. https://doi.org/10.1007/978-1-349-26040-9_8 Hayes, D. (2008). Does the Messenger Matter? Candidate-Media Agenda Convergence and Its Effects on Voter Issue Salience. Political Research Quarterly, 61(1), 134-146. https://doi.org/10.1177/1065912907306472

Hobolt, S. B. (2014). A vote for the President? The role of Spitzenkandidaten in the 2014 European Parliament elections. Journal of European Public Policy, 21(10), 1528-1540. https://doi.org/10.1080/13501763.2014.941148

Hopmann, D. N., Elmelund-Præstekær, C., Albæk, E., Vliegenthart, R., \& Vreese, C. H. de. (2012). Party media agenda-setting. Party Politics, 18(2), 173-191.

https://doi.org/10.1177/1354068810380097

Janda, K., \& Colman, T. (1998). Effects of Party Organization on Performance during the 'Golden Age' of Parties. Political Studies, 46(3), 611-632. https://doi.org/10.1111/14679248.00157

Jungherr, A. (2016). Twitter use in election campaigns: A systematic literature review. Journal of Information Technology \& Politics, 13(1), 72-91.

Katz, E., \& Lazarsfeld, P. M. (1955). Personal Influence: The Part Played by People in the Flow of Mass Communication. New York: Free Press. 
Larsson, A. O. (2015). The EU Parliament on Twitter - Assessing the Permanent Online Practices of Parliamentarians. Journal of Information Technology \& Politics, 12(2), $149-166$.

Lecheler, S., \& de Vreese, C. H. (2017). News Media, Knowledge, and Political Interest: Evidence of a Dual Role From a Field Experiment. Journal of Communication, 67(4), 545-564. https://doi.org/10.1111/jcom.12314

Levendusky, M. (2013). Partisan Media Exposure and Attitudes Toward the Opposition. Political Communication, 30(4), 565-581. https://doi.org/10.1080/10584609.2012.737435

Luskin, R. (1990). Explaining Political Sophistication. Political Behavior, 12(4), 331-361. Maier, M., Bacherle, P., Adam, S., \& Leidecker-Sandmann, M. (2017). The interplay between parties and media in putting EU issues on the agenda. Party Politics, 135406881770053. https://doi.org/10.1177/1354068817700532

Nulty, P., Theocharis, Y., Popa, S. A., Parnet, O., \& Benoit, K. (2016). Social media and political communication in the 2014 elections to the European Parliament. Electoral Studies, 44, 429-444. https://doi.org/10.1016/j.electstud.2016.04.014

Parmelee, J. H. (2014). The agenda-building function of political tweets. New Media \& Society, 16(3), 434-450. https://doi.org/10.1177/1461444813487955

Patterson, T. E. (1993). Out of Order. New York: Alfred A. Knopf.

Popa, S. A. (2015). Political sophistication in Central and Eastern Europe: How can parties help? Party Politics, 21(3), 440-455. https://doi.org/10.1177/1354068813487104

Popa, S. A., \& Dumitrescu, D. (2015). National but European? Visual manifestations of Europe in national parties' Euromanifestos since 1979. Party Politics.

Popa, S. A., Rohrschneider, R., \& Schmitt, H. (2016). Polarizing Without Legitimizing: The Effect of Lead Candidates' Campaigns on Perceptions of the EU Democracy. Electoral 
Studies, 44, 469-482.

Prior, M., Sood, G., \& Khanna, K. (2015). You Cannot be Serious. The Impact of Accuracy Incentives on Partisan Bias in Reports of Economic Perceptions. Quarterly Journal of Political Science, 10(July), 489-518. https://doi.org/10.1561/100.00014127

Schmitt, H., Braun, D., Popa, S. A., Mikhaylov, S., \& Dwinger, F. (2016). EUNGAGE European Parliament Election Study 2014, Euromanifesto Study Title. GESIS Data Archive, Cologne. ZA5162 Data File Version 1.0.0, Doi:10.4232/1.5162.

Schmitt, H., Hobolt, S. B., \& Popa, S. A. (2015). Does personalization increase turnout? Spitzenkandidaten in the 2014 European Parliament elections. European Union Politics, 16(3), 347-368. https://doi.org/10.1177/1465116515584626

Schmitt, H., Hobolt, S. B., Popa, S. A., Teperoglou, E., \& European Parliament, DirectorateGeneral for Communication, P. M. U. (2015). European Parliament Election Study 2014, Voter Study. GESIS Data Archive, Cologne. ZA5160 Data File Version 3.0.0, Doi:10.4232/1.12384.

Shehata, A., \& Strömbäck, J. (2018). Learning Political News From Social Media: Network Media Logic and Current Affairs News Learning in a High-Choice Media Environment. Communication Research, 009365021774935.

https://doi.org/10.1177/0093650217749354

Sunstein, C. (2001). Echo Chambers: Bush v. Gore, Impeachment, and Beyond. Princeton, NJ: Princeton University Press.

Taber, C., \& Lodge, M. (2006). Motivated skepticism in the evaluation of political beliefs. American Journal of Political Science, 50(3), 755-769.

Theocharis, Y., Barberá, P., Fazekas, Z., Popa, S. A., \& Parnet, O. (2016). A Bad Workman Blames His Tweets: The Consequences of Citizens' Uncivil Twitter Use When Interacting With Party Candidates. Journal of Communication, 66(6), 1007-1031. 
Topf, R. (1994). Party Manifestos. In Anthony Heath, R. Jowell, \& J. Curtice (Eds.), Labour's Last Chance?The Election of 1992 andBeyond (pp. 149-71). VT: Dartmouth. Vaccari, C., \& Valeriani, A. (2015). Follow the leader! Direct and indirect flows of political communication during the 2013 Italian general election campaign. New Media \& Society, 17(7), 1025-1042. https://doi.org/10.1177/1461444813511038

Van Dalen, A., Fazekas, Z., Klemmensen, R., \& Hansen, K. M. (2015). Policy Considerations on Facebook: Agendas, Coherence, and Communication Patterns in the 2011 Danish Parliamentary Elections. Journal of Information Technology \& Politics, 12(3), 303-324. https://doi.org/10.1080/19331681.2015.1061398

Vegetti, F., Fazekas, Z., \& Méder, Z. Z. (2016). Sorting your way out: Perceived party positions, political knowledge, and polarization. Acta Politica, 1-23. https://doi.org/10.1057/s41269-016-0029-6

Zaller, J. (1992). The nature and origins of mass opinion. Cambridge, MA.: Cambridge University Press. 


\title{
Online Supplementary Information for
}

\author{
"Informing the Public: \\ How Party Communication Builds Opportunity Structures"
}

\author{
Sebastian A. Popa \\ Newcastle University/ MZES, Mannheim \\ Sebastian.popa@ncl.ac.uk
}

Zoltán Fazekas

Department of International Economics, Government and Business, Copenhagen Business School zoltan.fazekas@gmail.com

Daniela Braun

LMU Munich/ MZES, Mannheim (External Fellow)

daniela.braun@gsi.uni-muenchen.de

Melanie-Marita Leidecker-Sandmann

Karlsruhe Institute of Technology (KIT)

leidecker-sandmann@kit.edu 


\section{Supplementary Information 1: Data description}

Table SI1.1: Party level descriptive summary

\begin{tabular}{|c|c|c|c|c|c|c|c|c|c|}
\hline & $\mathrm{n}$ & Party & Cand & Tw. & $\begin{array}{c}\text { Cands } \\
\text { mention }\end{array}$ & $\begin{array}{c}\text { Spitzen } \\
\text { reach }\end{array}$ & $\begin{array}{c}\text { Manifesto } \\
\text { salience }\end{array}$ & $\begin{array}{c}\mathrm{N} \\
\text { press }\end{array}$ & $\begin{array}{l}\mathrm{N} \text { press } \\
\text { mention }\end{array}$ \\
\hline \multirow[t]{6}{*}{ AT } & 87 & The Greens & 10 & 1817 & 5 & 185797 & 0.707 & 188 & 9 \\
\hline & 161 & Austrian Social Democratic Party & 13 & 2319 & 7 & 250933 & 0 & 519 & 47 \\
\hline & 104 & Austrian Freedom Party & 5 & 891 & 5 & 27330 & 0 & 222 & 21 \\
\hline & 35 & NEOS & 9 & 846 & 4 & 10658 & 0 & 54 & 0 \\
\hline & 121 & Austrian People's Party & 11 & 397 & 5 & 67197 & 0.656 & 305 & 33 \\
\hline & 5 & Alliance for the Future of Austria & 7 & 9349 & 3 & 215873 & & 120 & 4 \\
\hline \multirow[t]{11}{*}{$\mathrm{BE}$} & 30 & Ecologists & 2 & 44 & 1 & 585 & 0.057 & & \\
\hline & 46 & Green & 1 & 141 & 1 & 48928 & 0 & & \\
\hline & 28 & Centre Democrate Humaniste & & & & & 0.086 & & \\
\hline & 103 & Francophone Socialist Party & 4 & 186 & 2 & 5218 & 0 & & \\
\hline & 13 & Workers Party of Belgium & 2 & 191 & 1 & 1493 & & & \\
\hline & 51 & Socialist Party Different & 4 & 737 & 2 & 17283 & 0 & & \\
\hline & 45 & Open Flemish Liberals and Democrats & 2 & 52 & 2 & 1818 & 0 & & \\
\hline & 80 & Reform Movement & 4 & 211 & 0 & 0 & 0 & & \\
\hline & 78 & Christian Democratic and Flemish Party & 2 & 21 & 1 & 3621 & 0 & & \\
\hline & 25 & Flemish Interest & 1 & 198 & 1 & 38087 & 0 & & \\
\hline & 118 & New Flemish Alliance & 1 & 11 & 1 & 1763 & 0 & & \\
\hline \multirow[t]{7}{*}{ BG } & 128 & Coalition for Bulgaria & 2 & 18 & 0 & 0 & 0 & & \\
\hline & 165 & CEDB & 5 & 88 & 1 & 1335 & 0 & & \\
\hline & 23 & Reformist Bloc & 2 & 238 & 1 & 3046 & 0 & & \\
\hline & 21 & BG coalition $(2)$ & & & & & 0 & & \\
\hline & 22 & Attack & 1 & 27 & 0 & 0 & 0 & & \\
\hline & 27 & Movement for Rights and Freedom & 1 & 203 & 0 & 0 & 0 & & \\
\hline & 7 & Altertive for Bulgarian Revival & 1 & 150 & 1 & 2968 & & & \\
\hline \multirow[t]{5}{*}{ HR } & 80 & Odræivi razvoj Hrvatske & & & & & 0 & & \\
\hline & 83 & Social Democratic Party of Croatia & 5 & 220 & 2 & 5008 & 0 & & \\
\hline & 17 & Croatian Labouristi - Labour Party & 1 & 37 & 0 & 0 & & & \\
\hline & 5 & Croatian Social-Liberal Party & 1 & 65 & 1 & 1678 & & & \\
\hline & 157 & Croation Democratic Union & 6 & 409 & 0 & 0 & 0 & & \\
\hline \multirow[t]{4}{*}{ CYP } & 63 & Progressive Party of the Working People & 1 & 1 & 0 & 0 & 0 & & \\
\hline & 22 & Social Democrats' Movement & 1 & 43 & 0 & 0 & 0 & & \\
\hline & 30 & Democratic Party & 3 & 187 & 0 & 0 & 0 & & \\
\hline & 87 & Democratic Coalition & 1 & 145 & 1 & 8158 & 0 & & \\
\hline \multirow[t]{8}{*}{$\mathrm{CZ}$} & 25 & Green Party & 1 & 82 & 1 & 16492 & & & \\
\hline & 98 & Communist Party of Bohemia and Moravia & 3 & 88 & 0 & 0 & 0 & & \\
\hline & 146 & Czech Social Democratic Party & 5 & 97 & 1 & 955 & 2.353 & & \\
\hline & 49 & Civic Democratic Party & 6 & 136 & 2 & 739 & 0 & & \\
\hline & 203 & ANO 2011 & 3 & 107 & 2 & 812 & 0.227 & & \\
\hline & 39 & C and Dem Union / Czechoslovak People's Party & 5 & 239 & 2 & 414 & 0.549 & & \\
\hline & 56 & TOP 09 & 5 & 58 & 1 & 300 & 0.428 & & \\
\hline & 14 & Party of Free Citizens & 2 & 535 & 1 & 1141 & 0.209 & & \\
\hline \multirow[t]{8}{*}{ DK } & 218 & Social Democratic Party & 7 & 887 & 1 & 1106 & 0 & & \\
\hline & 66 & Socialist People's Party & 6 & 405 & 1 & 187 & 0 & & \\
\hline & 55 & Radical Party & 7 & 2263 & 4 & 99194 & 0 & & \\
\hline & 182 & Liberals & 5 & 187 & 1 & 1667 & 0 & & \\
\hline & 17 & Liberal Alliance & 2 & 210 & 1 & 640 & & & \\
\hline & 38 & Conservative People's Party & 5 & 405 & 1 & 511 & 0.847 & & \\
\hline & 164 & Danish People's Party & 4 & 295 & 2 & 10565 & 0 & & \\
\hline & 19 & People's Movement against EU & 6 & 198 & 0 & 0 & 0 & & \\
\hline $\mathrm{EE}$ & 17 & Independent & 5 & 171 & 1 & 299 & & & \\
\hline & 96 & Social Democratic Party & 2 & 30 & 0 & 0 & 0.424 & & \\
\hline & 95 & Estonian Center Party & 1 & 16 & 0 & 0 & 0 & & \\
\hline & 82 & Estonian Reform Party & 3 & 154 & 0 & 0 & 0 & & \\
\hline & 48 & Pro Patria and Res Publica Union & 6 & 560 & 1 & 4093 & 0 & & \\
\hline FI & 59 & Green Union & 17 & 3917 & 11 & 231287 & 0 & & \\
\hline & 44 & Left Wing Alliance & 11 & 1144 & 4 & 16678 & 0 & & \\
\hline & 97 & Finnish Social Democrats & 17 & 1393 & 3 & 16103 & 0 & & \\
\hline & 30 & Christian Democrats in Finland & 13 & 751 & 1 & 152 & 0 & & \\
\hline & 157 & tiol Coalition & 15 & 2800 & 2 & 119508 & 0 & & \\
\hline & 144 & Finnish Centre & 16 & 1257 & 3 & 31841 & 0 & & \\
\hline & 53 & True Finns & 11 & 399 & 0 & 0 & 0 & & \\
\hline & 16 & Swedish People's Party & 8 & 446 & 3 & 2918 & 0 & & \\
\hline FR & 51 & Europe Ecology - The Greens & 36 & 6451 & 25 & 2609897 & 0.333 & 43 & 2 \\
\hline & 42 & Left Front & 21 & 4264 & 16 & 1486122 & 0.238 & 108 & 8 \\
\hline & 6 & NPA & & & & & & 16 & 0 \\
\hline & 177 & Socialist Party & 42 & 7188 & 33 & 2220223 & & 48 & 4 \\
\hline & 45 & UDI + MoDem & 39 & 6973 & 27 & 596626 & 1.364 & 8 & 2 \\
\hline & 114 & Union for a Popular Movement & 44 & 4162 & 12 & 523493 & 0 & & \\
\hline & 3 & Arise the Republic & 7 & 965 & 2 & 6844 & & & \\
\hline & 66 & $\mathrm{FN}$ & 28 & 2376 & 12 & 996377 & 0 & 111 & 2 \\
\hline $\mathrm{DE}$ & 102 & Alliance 90 / The Greens & 15 & 2345 & 12 & 1834798 & 0.045 & 120 & 2 \\
\hline & 292 & Social Democratic Party & 21 & 2238 & 17 & 391904 & 0.776 & 174 & 39 \\
\hline & 105 & The Left & 3 & 22 & 0 & 0 & 0.05 & 143 & 0 \\
\hline
\end{tabular}




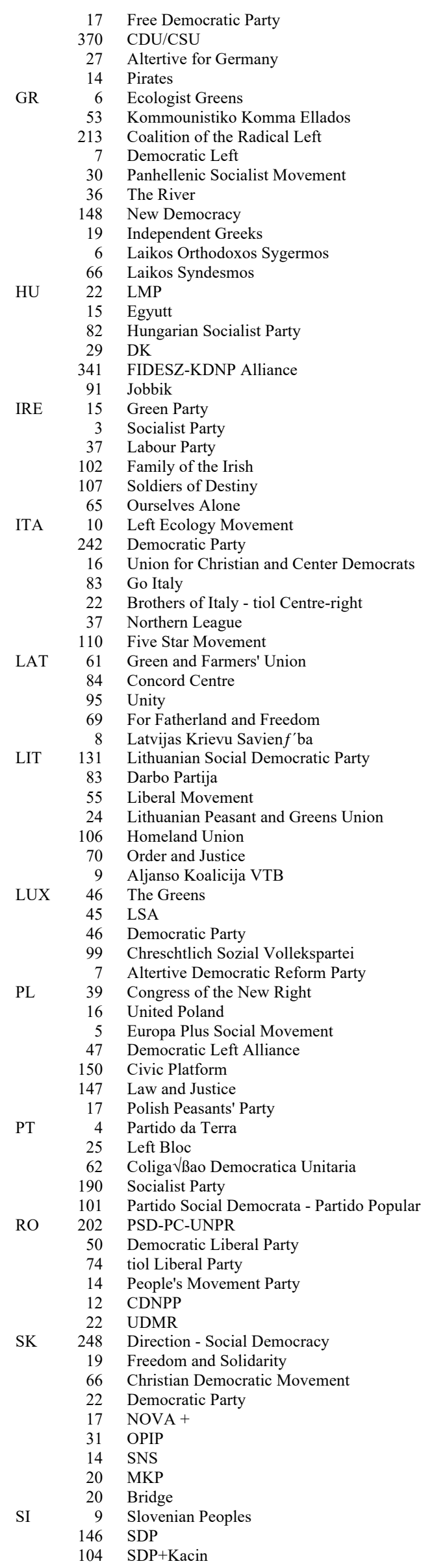

\begin{tabular}{|c|c|c|c|c|c|c|}
\hline 21 & 1470 & 11 & 116989 & 0.109 & 50 & 11 \\
\hline 22 & 1023 & 21 & 316179 & 0 & 108 & 4 \\
\hline 3 & 13 & 0 & 0 & 0 & 32 & 5 \\
\hline 11 & 5922 & 7 & 157114 & 0 & & \\
\hline \multirow[t]{2}{*}{8} & 451 & 3 & 1488 & 0 & 46 & 0 \\
\hline & & & & 0.195 & 64 & 0 \\
\hline 15 & 1464 & 9 & 318484 & 0.554 & 334 & 35 \\
\hline 9 & 490 & 1 & 2371 & & 72 & 1 \\
\hline 16 & 1761 & 6 & 152383 & 0.912 & 65 & 11 \\
\hline 8 & 512 & 4 & 7571 & 0 & & \\
\hline 18 & 1415 & 4 & 11559 & 1.17 & 62 & 14 \\
\hline \multirow[t]{5}{*}{7} & 410 & 0 & 0 & 0 & 182 & 0 \\
\hline & & & & 0 & 33 & 2 \\
\hline & & & & 0 & 67 & 1 \\
\hline & & & & 0 & & \\
\hline & & & & 0 & & \\
\hline \multirow[t]{2}{*}{2} & 138 & 1 & 16805 & 1.099 & & \\
\hline & & & & 0 & & \\
\hline \multirow[t]{2}{*}{3} & 18 & 0 & 0 & 0 & & \\
\hline & & & & 0 & & \\
\hline 3 & 356 & 3 & 69998 & 0 & & \\
\hline 1 & 149 & 0 & 0 & 0 & & \\
\hline 2 & 735 & 1 & 16729 & 0 & & \\
\hline 6 & 1029 & 1 & 3903 & 0 & & \\
\hline 2 & 244 & 1 & 1777 & 0 & & \\
\hline 3 & 536 & 0 & 0 & 0 & & \\
\hline 20 & 3406 & 19 & 1099321 & 0 & & \\
\hline 34 & 7488 & 19 & 1021255 & 0 & & \\
\hline 44 & 5041 & 13 & 116158 & & & \\
\hline 45 & 12968 & 13 & 83979 & & & \\
\hline 35 & 11877 & 11 & 443456 & & & \\
\hline 22 & 11651 & 6 & 936284 & 0 & & \\
\hline 29 & 3372 & 7 & 73991 & 0 & & \\
\hline 6 & 425 & 0 & 0 & 0 & & \\
\hline 3 & 32 & 0 & 0 & 0 & & \\
\hline 14 & 2399 & 7 & 84199 & 0 & & \\
\hline \multirow[t]{2}{*}{11} & 231 & 0 & 0 & 0 & & \\
\hline & & & & 0 & & \\
\hline \multirow[t]{2}{*}{2} & 10 & 0 & 0 & 0.169 & & \\
\hline & & & & 0 & & \\
\hline 7 & 318 & 0 & 0 & 0 & & \\
\hline 1 & 15 & 0 & 0 & 0 & & \\
\hline 4 & 67 & 0 & 0 & 0 & & \\
\hline 1 & 2 & 0 & 0 & 0 & & \\
\hline & & & & 0 & & \\
\hline 1 & 2 & 1 & 563 & 0 & & \\
\hline & & & & 0 & & \\
\hline 3 & 5 & 1 & 425 & 0.231 & & \\
\hline & & & & 0.704 & & \\
\hline 1 & 2 & 0 & 0 & & & \\
\hline 2 & 258 & 0 & 0 & 0 & & \\
\hline 4 & 178 & 0 & 0 & & & \\
\hline 48 & 3764 & 6 & 9919 & & & \\
\hline 6 & 309 & 2 & 38738 & 0 & & \\
\hline 30 & 3151 & 5 & 75302 & 0 & & \\
\hline 14 & 902 & 0 & 0 & 0 & & \\
\hline 14 & 1003 & 1 & 4230 & 0 & & \\
\hline & & & & 0 & & \\
\hline 1 & 53 & 0 & 0 & 0 & 100 & 10 \\
\hline & & & & 0 & 87 & 0 \\
\hline 3 & 360 & 1 & 52414 & 0 & 176 & 7 \\
\hline & & & & 0 & 77 & 11 \\
\hline 1 & 2 & 0 & 0 & 0.129 & & \\
\hline 2 & 223 & 2 & 3410 & 0.526 & & \\
\hline 2 & 18 & 2 & 13021 & 0 & & \\
\hline 2 & 34 & 1 & 5044 & 0.821 & & \\
\hline 1 & 1 & 0 & 0 & & & \\
\hline 3 & 77 & 0 & 0 & 0 & & \\
\hline 2 & 34 & 0 & 0 & 0.881 & & \\
\hline 4 & 89 & 1 & 93 & 0 & & \\
\hline 2 & 31 & 0 & 0 & 0 & & \\
\hline 2 & 32 & 0 & 0 & 0 & & \\
\hline & & & & 0 & & \\
\hline 4 & 204 & 1 & 170 & 0 & & \\
\hline & & & & 0 & & \\
\hline & & & & 0 & & \\
\hline 1 & 112 & 0 & 0 & 0 & & \\
\hline 2 & 363 & 1 & 20933 & 0 & & \\
\hline 5 & 907 & 2 & 33674 & 0 & & \\
\hline 11 & 1204 & 6 & 64930 & 0 & & \\
\hline
\end{tabular}




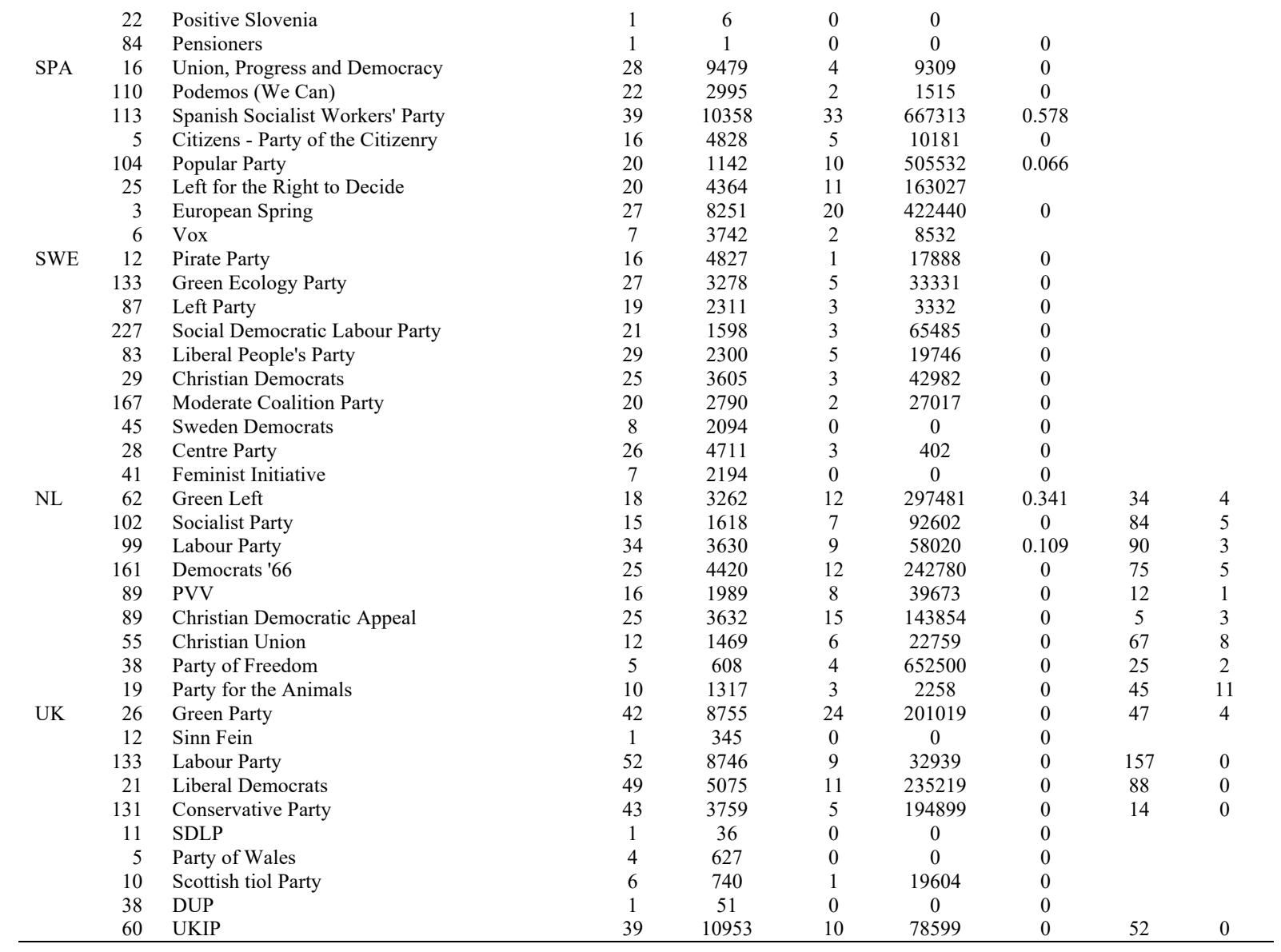

Notes: Cand $=$ number of candidates on Twitter. $\mathrm{Tw}=$ tweets. Cands. mention $=$ number of candidates who mention the Spitzenkandidaten. Manifesto salience expressed in percentage. 
Figure SI1.1: Distribution of Spitzenkandidaten recognition

Outcome distribution, voter level

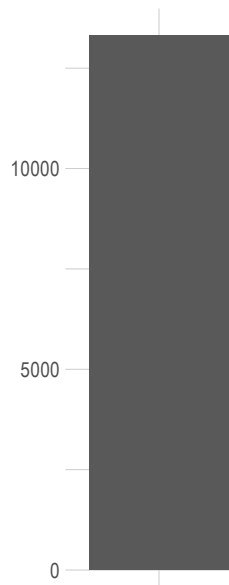

$0 / 3$

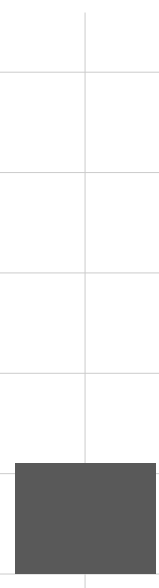

$1 / 3$

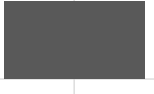

$2 / 3$
Outcome distribution, party averages

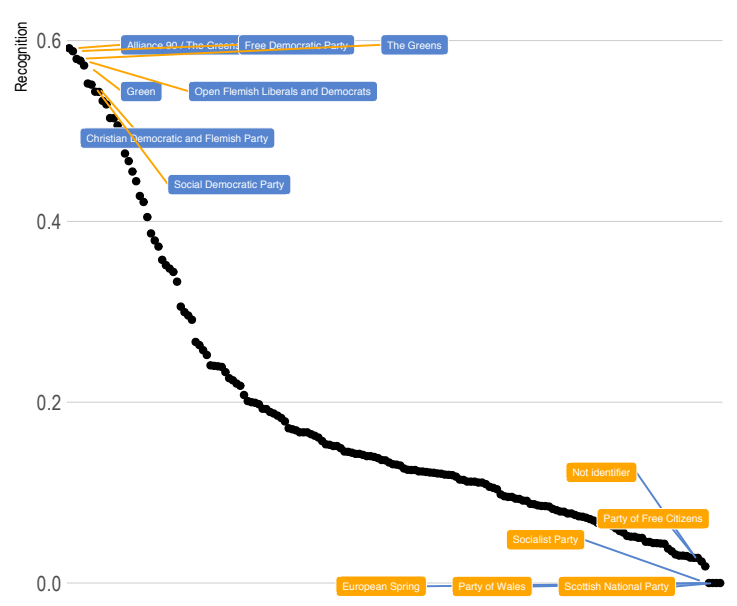

$3 / 3$ 
Table SI1.2: Recognition descriptive statistics, as $\%$ of respondents

\begin{tabular}{rcccc}
\hline & No correct & 1 correct & 2 correct & All correct \\
\hline Austria & 42.92 & 19.79 & 24.17 & 13.12 \\
Belgium & 23.07 & 40.75 & 15.34 & 20.84 \\
Bulgaria & 73.16 & 12.12 & 10.58 & 4.14 \\
Croatia & 81.41 & 9.23 & 6.54 & 2.82 \\
Cyprus & 73.25 & 16.11 & 6.99 & 3.65 \\
Czech Republic & 89.05 & 6.62 & 3.13 & 1.2 \\
Denmark & 74.7 & 16.71 & 6.42 & 2.18 \\
Estonia & 91.3 & 5.52 & 1.8 & 1.38 \\
Finland & 66.06 & 17.08 & 8.09 & 8.77 \\
France & 76.5 & 10.83 & 10.4 & 2.28 \\
Germany & 22.56 & 14.07 & 55.74 & 7.63 \\
Greece & 68.41 & 15.67 & 8.51 & 7.41 \\
Hungary & 79.95 & 12.85 & 4.63 & 2.57 \\
Ireland & 80.28 & 15.38 & 3.5 & 0.84 \\
Italy & 67.5 & 16.69 & 8.71 & 7.09 \\
Latvia & 80.77 & 14.66 & 2.35 & 2.21 \\
Lithuania & 86.67 & 8.3 & 2.72 & 2.31 \\
Luxembourg & 12.26 & 38.69 & 27.79 & 21.25 \\
Poland & 86.21 & 9.34 & 2.73 & 1.72 \\
Portugal & 78.23 & 13.71 & 4.52 & 3.55 \\
Romania & 80.67 & 12.79 & 4.65 & 1.89 \\
Slovakia & 84.5 & 11.63 & 2.45 & 1.42 \\
Slovenia & 74.04 & 8.23 & 5.96 & 11.77 \\
Spain & 83.09 & 6.94 & 6.94 & 3.03 \\
Sweden & 72.89 & 17.48 & 6.55 & 3.08 \\
The Netherlands & 63.31 & 17.29 & 6.04 & 13.36 \\
United Kingdom & 84.28 & 13.69 & 1.47 & 0.57 \\
\hline & & & & \\
\hline & & & \\
\hline
\end{tabular}


Table SI1.3: Correctly linked candidate to party, as \% of respondents

\begin{tabular}{|c|c|c|c|}
\hline & Juncker & Schulz & Verhofstadt \\
\hline Austria & 45 & 40.73 & 16.04 \\
\hline Belgium & 30.95 & 25.81 & 70.09 \\
\hline Bulgaria & 14.32 & 17.98 & 5.27 \\
\hline Croatia & 13 & 11.7 & 4.23 \\
\hline Cyprus & 17 & 11.82 & 6.4 \\
\hline Czech Republic & 5.07 & 6.24 & 3.49 \\
\hline Denmark & 17.71 & 11.11 & 3.35 \\
\hline Estonia & 4.28 & 5.05 & 2.09 \\
\hline Finland & 26 & 18.01 & 12.08 \\
\hline France & 13.53 & 17.72 & 2.75 \\
\hline Germany & 65.69 & 68.92 & 7.82 \\
\hline Greece & 23.1 & 19.08 & 10.04 \\
\hline Hungary & 9.78 & 10.65 & 6.3 \\
\hline Ireland & 13.68 & 4.7 & 1.71 \\
\hline Italy & 14.66 & 23.72 & 9.89 \\
\hline Latvia & 15.24 & 4.44 & 2.96 \\
\hline Lithuania & 5.97 & 8.03 & 4.56 \\
\hline Luxembourg & 82.76 & 48.28 & 23.89 \\
\hline Poland & 4.82 & 7.39 & 4.18 \\
\hline Portugal & 13.05 & 10.12 & 5.46 \\
\hline Romania & 5.72 & 12.5 & 3.81 \\
\hline Slovakia & 6.78 & 7.12 & 4.97 \\
\hline Slovenia & 19.88 & 18.26 & 11.18 \\
\hline Spain & 10.78 & 10.33 & 3.52 \\
\hline Sweden & 21.22 & 11.77 & 5.1 \\
\hline The Netherlands & 24.14 & 16.45 & 24.83 \\
\hline United Kingdom & 9.32 & 3.63 & 1.98 \\
\hline
\end{tabular}




\section{Supplementary Information 2: Search validation}

We review here the strategy employed for selecting the distance threshold and results from an evaluation exercise viewed as part of a validation process. Before that, we reiterate from the main text how we handled the Twitter search, with an additional example. We are looking at Twitter with a 160-character limit where the text can be written on various devices, with abbreviations or potential spelling errors, especially in the case of names as they are not part of usual autocorrect dictionaries. We calculate distance (Jaro-Winkler) between each element of our thesaurus and terms of the same length (n-grams) from each Tweet. This generates a set of distance scores between each element of the Tweet and each term of the thesaurus. Across these values within one Tweet, we take the minimum distance and record that as the result of our search. Table SI2.1 displays this process with a hypothetical Tweet being "Schultz is best for the EU" and the subset of the thesaurus pertaining to Martin Schulz.

Table SI2.1: Generating distance

\begin{tabular}{llccc}
\hline \multicolumn{1}{c}{ Tweet (split) } & Vocabulary element & JW score & Minimums & Final score \\
\hline the & Schulz & 0.5 & & \\
schultz & Schulz & $\mathbf{0 . 0 4 7 6}$ & & \\
is & Schulz & 0.4444 & & \\
for & Schulz & 1 & 0.0476 & \\
best & Schulz & 0.5278 & & \\
EU & Schulz & 1 & & $\mathbf{0 . 0 4 7 6}$ \\
the EU & martin schulz & 0.5042 & & \\
is best & martin schulz & 0.5402 & & \\
for the & martin schulz & $\mathbf{0 . 4 5 6 9}$ & 0.4569 & \\
schultz is & martin schulz & 0.5141 & & \\
best for & martin schulz & 0.4807 & & \\
\hline
\end{tabular}

\section{Cut point selection through human validation}

As reported in the text, we tag a Tweet a mention of the candidate or position element of interest if the distance metric is below 0.05 . We report here the general strategy and validation exercise covering the UK, Germany, Czech Republic, Slovakia, and France for the quantities of interest. In these countries, we selected Tweets that had an approximate distance score between 0 and 0.15 (reminder: 0 indicates at least one perfect match from at least one element of our thesaurus), for any of the thesaurus of interest. To be more precise, these are Tweets from candidates running in these countries, not necessarily Tweets in the given country's language. 
Given available resources we were able to assign all Tweets in question from the Czech Republic, Slovakia, and the UK to one coder, and a random subsample of 1000 Tweets from Germany and 1000 Tweets from France to another coder (with different language skills). The two coders were student assistants at the Mannheim Centre for European Social Research (MZES). Since this is a follow-up checking task with a thesaurus supplied and the resources were limited, each Tweet was coded only by one coder, hence no inter-coder reliability was calculated. The task followed exactly the automated search task: coders were asked to mark for each candidate appearance in the text $(0=$ no, $1=$ yes $)$, and the same for the institution related search terms, with the exact list of terms supplied prior to the coding. Thus, we evaluate here the automated text coding, rather than the relationship between the concept and the used terms (not a validation exercise of the thesaurus used). We discarded Tweets that were highlighted to be in a language in which coders were not able to code the content.

As our paper focuses on any mention, we have recoded the human annotation to be 1 if any relevant feature is found, 0 otherwise. Of course, there were multiple Tweets that mentioned more than one candidate, or candidates and institutional terms together. We use the results of the human coding as gold standard, and calculate accuracy, precision, and recall for different cutoff thresholds of our machine search. ${ }^{1}$

Figure SI2.1: Contrasting human coding and search results for different distance thresholds
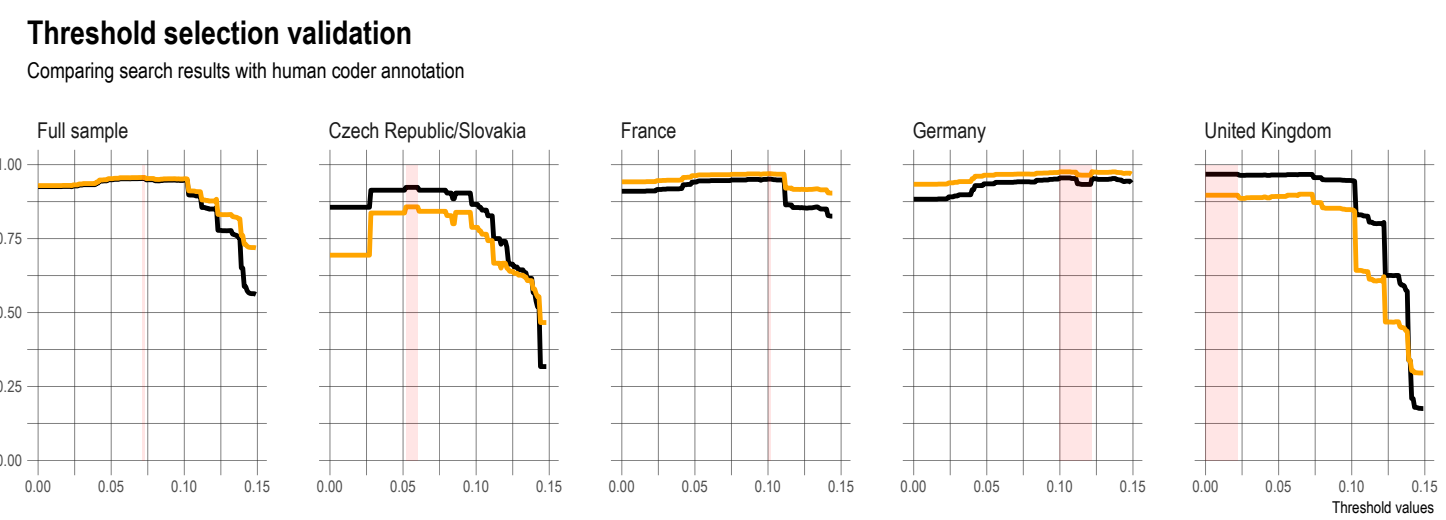

Black line: accuracy. Orange line: F-score (harmonic mean of precision and recall).

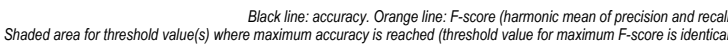

\footnotetext{
${ }^{1}$ Accuracy is the proportion of tweets correctly identified; precision is the proportion of tweets with predicted value of mention correctly classified; recall is the proportion of tweets with predicted value of no mention correctly classified.
} 
Figure SI2.1 displays the relationship between the distance metric threshold and the result of the human coding, focusing on accuracy and F-score (harmonic mean of precision and recall). Overall, we see good performance compared to our human coding. If all countries considered, the optimal threshold would be 0.06 , which is slightly higher (more tolerant) than what we employ. However, we also see that these optimal thresholds vary across countries. While only a subset of countries was included in the validation, it is important to note that our current threshold and approach definitely assures that 1) we do not have false positives, limiting potential issues in the UK, and 2) results in better depiction of social media communication search than identifying only exact matches, with partially reducing false negatives in Germany. Since there is a between platform comparison component in the main paper, we use the more conservative measure as we especially want to avoid false positives. With generally low salience of the Spitzenkandidaten, we do not want our social media results to be driven by potential overestimation of salience compared to the two other communication platforms analyzed.

Face validity: lead candidate debate and frequency of mentions

A second way to check for face validity is linking the frequency of mentions to an important campaign event. One such event was the televised lead candidate debate held on $15^{\text {th }}$ of May 2014 in Brussels (EBU), with 5 of the lead candidates present. Figure SI2.2 displays the estimated mentions aggregated at the day level across all countries. We see that indeed, around the debate the mentions of lead candidate related terms peaks. Second, as displayed in Figure SI2.3 this peak holds also when we factor in the overall increase in the Tweets, lending further confidence in our content retrieval method and consequently the measurement of attention dedicated to lead candidates. 
Figure SI2.2: Spitzenkandidaten relevant mention count throughout the campaign

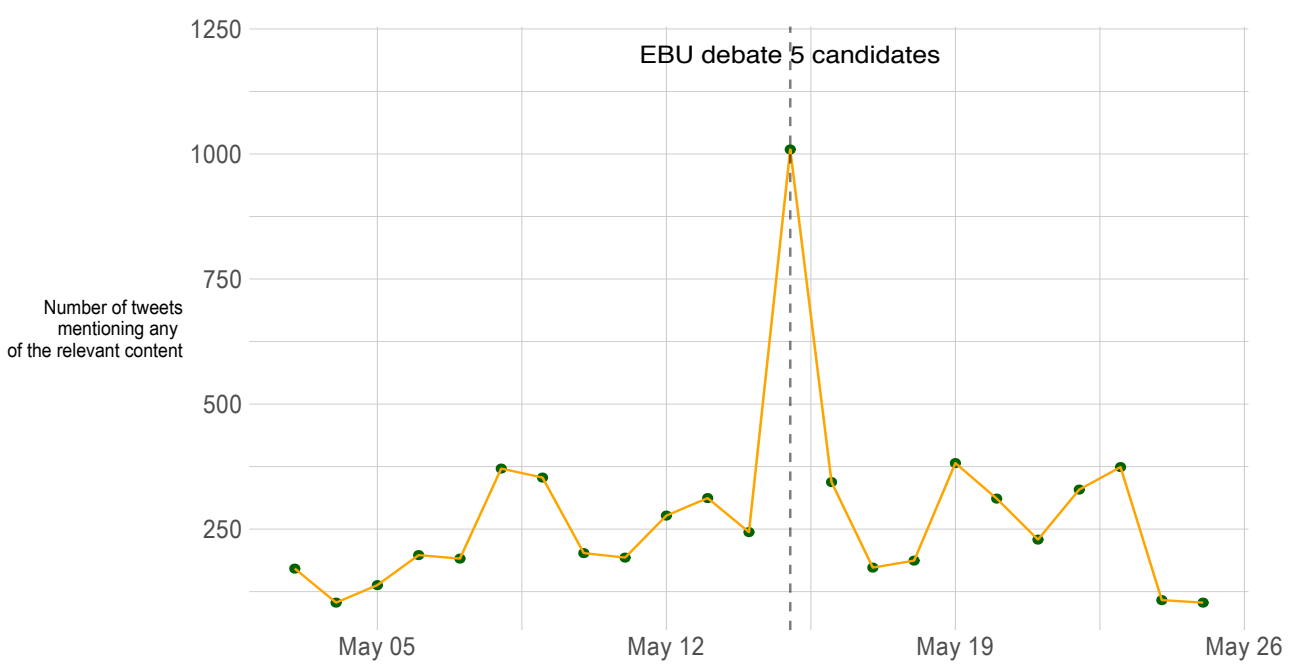

Figure SI2.3: Spitzenkandidaten relevant mention proportion (of total Tweets) throughout the campaign

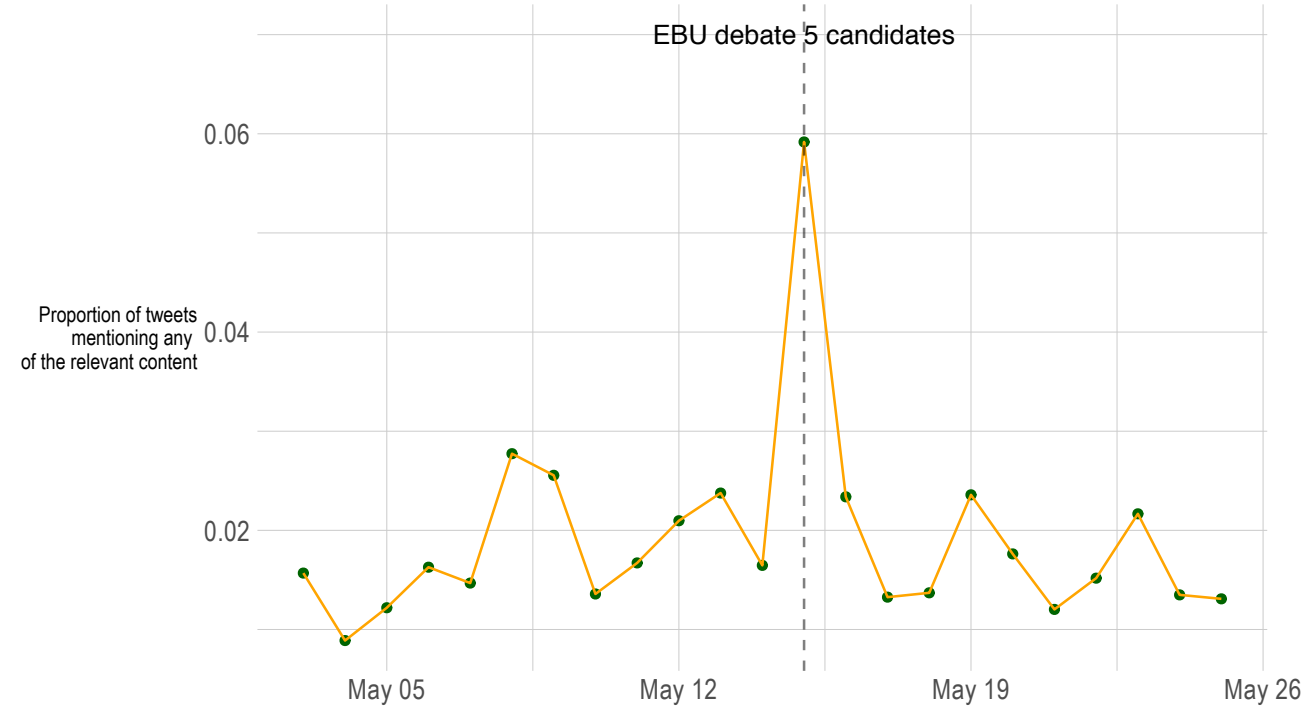




\section{Supplementary Information 3: Detailed description of Twitter outreach measure}

Our main measure relies on follower information that each candidate had at the moment of each Tweet sent. Accordingly, we treat the number of followers as possible outreach, or audience. As described in the main text, for party, we sum the total number of followers reached (all candidates, all Tweets) and the log of this count will be our denominator. In an identical manner, we sum the total number of followers but only including Tweets that mentioned the Spitzenkandidaten. The log of this count (adjust with +1 before $\log$ transformation) is our numerator. Overall, these steps assure that extremely high visibility and popularity candidates do not scale off the charts (through log) and that our outreach measure is still in line with the salience-based measures (through dividing by total outreach) on the other platforms.

Table SI3.1: Measure calculation example

\begin{tabular}{|c|c|c|c|c|c|}
\hline Party 1 & Content & Followers & Party 2 & Content & Followers \\
\hline Candidate 1 & & & Candidate 1 & & \\
\hline Tweet 1 & Spitzen & 1000 & Tweet 1 & Not Spitzen & 20000 \\
\hline Tweet 2 & Spitzen & 1100 & Tweet 2 & Not Spitzen & 22000 \\
\hline Tweet 3 & Not Spitzen & 1110 & Candidate 1 & & \\
\hline Candidate 1 & & & Tweet 1 & Spitzen & 30000 \\
\hline Tweet 1 & Spitzen & 1000000 & Tweet 2 & Spitzen & 30100 \\
\hline Tweet 2 & Not Spitzen & 1001000 & & & \\
\hline Party 1 & & & Party 2 & & \\
\hline Numerator & \multicolumn{2}{|c|}{$\log (1000+1100+1000000+\mathbf{1})$} & Numerator & \multicolumn{2}{|c|}{$\log (30000+30100+\mathbf{1})$} \\
\hline Denominator & \multicolumn{2}{|c|}{$\begin{array}{l}\log (1000+1100+1110+1000000+ \\
1001000)\end{array}$} & Denominator & \multicolumn{2}{|c|}{$\log (20000+22000+30000+30100)$} \\
\hline Final score: & 0.952 & & Final score: & 0.954 & \\
\hline
\end{tabular}

Note: per Tweet follower numbers can both increase and decrease. This reflects the changing number of people following each candidate depending of the time of Tweet. +1 is added to the numerator before taking the log.

First, in Table SI3.1 we present a hypothetical example of different candidates and Tweet content that exemplifies our measure calculation. Through this example we show that Tweets from overly popular candidates will not drive these numbers. While the measure pulls absolute numbers upwards, these should not be understood directly (1:1) salience or proportion outreach measures, given the transformations involved. We focus on between party comparisons and in our analysis, we mean center and rescale these predictors to better 
gauge relative patterns. We do not aim to formulate conclusions such as $\mathrm{X}$ amount increase in number of Tweets should mean $\mathrm{Y}$ amount of increase in recognition, as we believe those conclusions are misleading. Rather, we focus on a comparably scaled opportunity structure and between party differences.

Second, as displayed in Figure SI3.1, when calculating our outreach measure on a daily basis, we see good face validity: outreach is at its maximum on the day of the main Spitzenkandidaten debate, also peaking around the 8 May debate that was televised with good rating in Germany and Austria.

Figure SI3.1: Spitzenkandidaten relevant mention proportion (of total Tweets) throughout the campaign

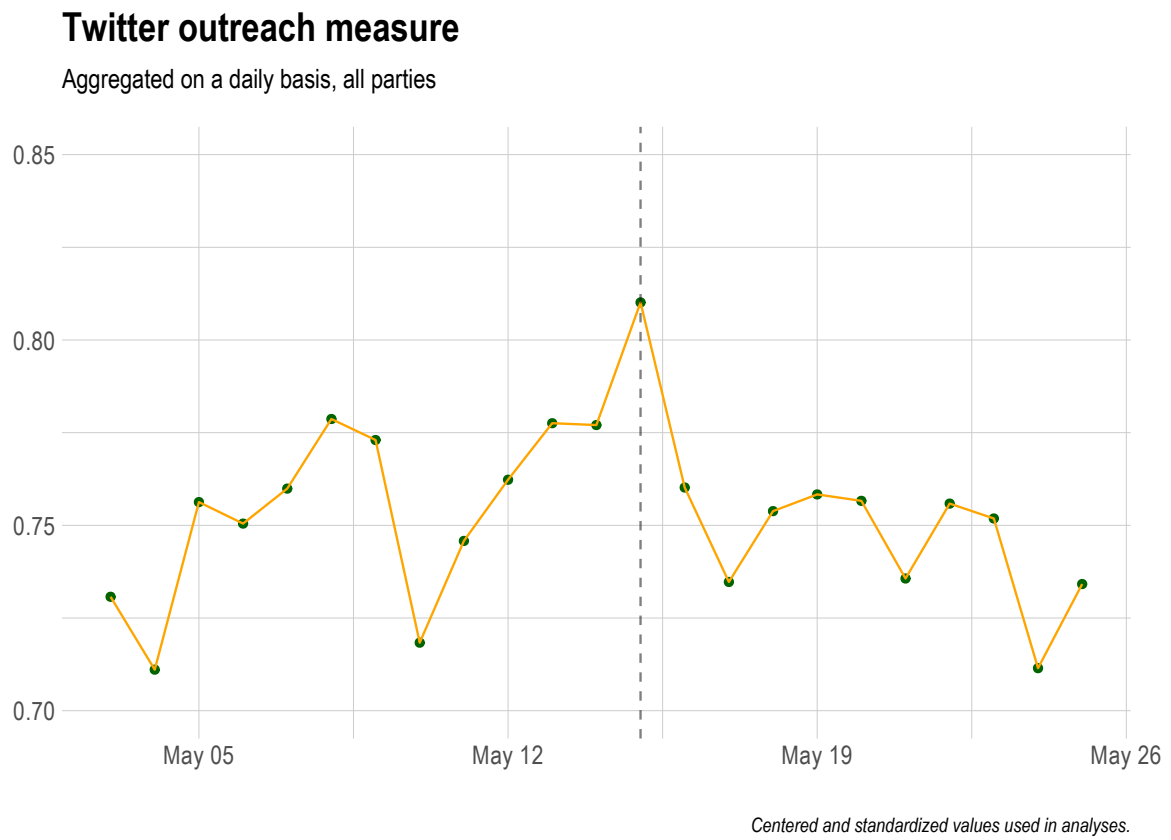

Finally, as referenced in the main text analysis section, we carry out several robustness tests, including those that alter the Twitter outreach measurement. The three alternatives presented are: (1) for each party, the proportion of candidates on Twitter mentioning at least once the Spitzenkandidaten, (2) the proportion of all Tweets sent by each party (total of candidates) mentioning the Spitzenkandidaten, and (3) the sum of all the potential followers reached by Spitzenkandidaten tweets (summed each Tweet following for each party) and divided by the number of votes the parties received in the 2014 EP elections. This last alternative is another way to account for party size differences on one hand, but also allows for better comparability or scaling between countries on the other hand. The first two 
alternatives are provided for a closer relationship with how the salience measures were calculated on other platforms. Below, in Table SI3.2 we summarize how the three alternative measures relate to our main Twitter outreach measure through Spearman's correlation coefficients. We prefer rank order correlations as these measures are on different scales. As seen, there is a very high correspondence between these.

Table SI3.2: Correspondence between different Twitter measures

\begin{tabular}{lccc}
\hline & Proportion candidates & $\begin{array}{c}\text { Proportion } \\
\text { tweets }\end{array}$ & Reach/votes in election \\
\hline $\begin{array}{l}\text { Ratio of log follower } \\
\text { count (original) }\end{array}$ & 0.89 & 0.93 & 0.86 \\
\hline
\end{tabular}


Supplementary Information 4: Variable description and detailed results from bivariate models and robustness tests

\section{Variable description}

Explanatory variables, individual component (level 1), Original questions available at the following link:

http://europeanelectionstudies.net/wp-content/uploads/2014/05/Master-Questionnaire.pdf.

Sex: original question D10, recoded to 1 'female' and 0 'men'.

Age: original question VD11.

Secondary education: original question VD11, recoded 1 for those who ended their education between the age of 16 and 19 and 0 otherwise.

Tertiary education: original question VD8, recoded 1 for those who ended their education after the age of 20 and 0 otherwise.

EU Knowledge: measure of political knowledge that ranges from 0 to 2, reflecting the correct True/False answers given by each respondent to. "Don't Know" answers were coded as incorrect answers as we consider that they reflect a degree of ignorance similar to the one reflected by incorrect answers.

QPP23.1. Switzerland is a member of the EU. True/False (correct answer: False)

QPP23.2 Each Member State elects the same number of representatives to the European Parliament. True/False (correct answer: False)

Interest in politics: original wording QP6.9 The original variable takes values between $1=$ "Yes, definitely" and $4=$ "No, not at all'. Scale was reversed so that low values reflect low interest in politics and high values reflect high interest in politics.

Campaign exposure: original wording QP8, responses was recoded to 0 reflecting 'No, not don't remember' and 1 reflecting 'yes, remember'.

Political discussion: a mean of three items (Cronbach alpha $=0.87)$. Scale was reversed so that low values reflect low frequencies of discussion and high values reflect high frequency of discussion. Original variables rescaled to $[0,1]$ range.

D71_1 discussion about national politics matters, 3-point scale 1 = "Frequently", 2 = "Occasionally" and 3 = "Never"

Dd71_2 Discussion about European politics matters, 3-point scale 1 = "Frequently", 2 = "Occasionally" and $3=$ "Never" 
D 71_3 Discussion about local politics matters), 3-point scale 1 = "Frequently", 2 = "Occasionally" and 3 = "Never"

EU position: original question wording QPP18 order was reversed and rescaled in the analysis, the final original variable takes values for 0 reflecting that the respondent considers that "European unification has already gone too far" to 10 reflecting that the respondent considers 'European unification should be pushed further.

News consumption: variable computed as the maximum of three items QP9.1 (TV news), QP9.2 (online news) and QP9.3 (newspaper news), each measured on scale ranging from 1 = "Every day/almost every day" to $6=$ "Never". Scale was reversed so that low values reflect low media consumption and high values reflect daily media consumptions.

Explanatory variables, party level (level-2):

Party of lead candidate: coded 1 for the national parties that supported any of the lead candidates in the runoff for the 2014 EP elections and 0 otherwise. 
Figure SI4.1: Manifesto mention distribution

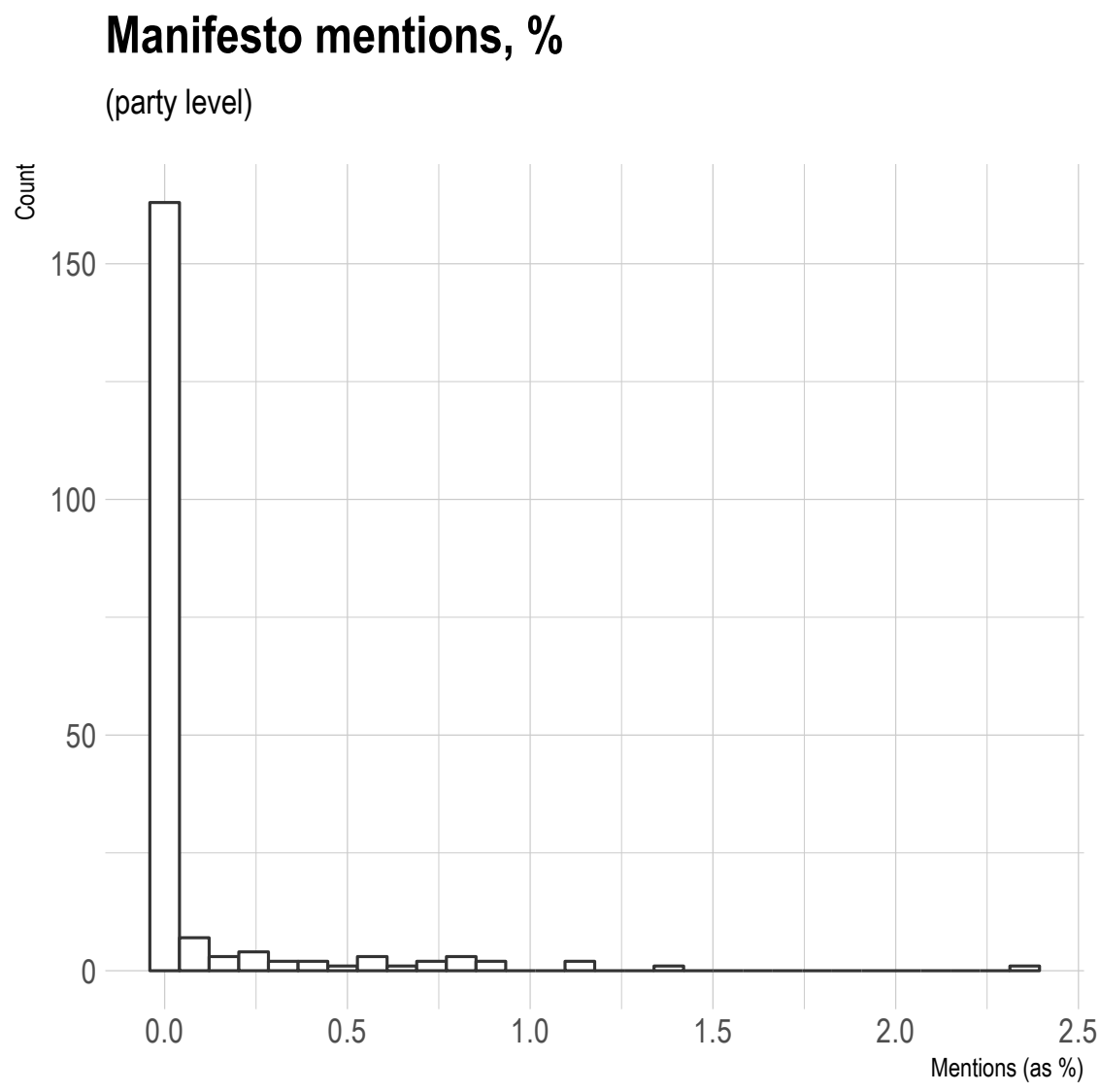


Bivariate models: Summary tables

Table SI4.1: Bivariate models (logit coefficients)

\begin{tabular}{lccc}
\hline & Twitter model & Manifesto model & Press model \\
\hline Intercept & $\mathbf{- 1 . 6 5}(0.06)$ & $\mathbf{- 1 . 8 5}(0.08)$ & $\mathbf{- 1 . 2 5}(0.12)$ \\
Twitter reach & $\mathbf{0 . 8 3}(0.12)$ & & \\
Manifesto mention $(=1)$ & & $\mathbf{0 . 4 9}(0.18)$ & \\
Press release salience & & & $0.39(0.25)$ \\
\hline AIC & 36181.86 & 36849.20 & 13281.47 \\
BIC & 36205.50 & 36872.89 & 13301.53 \\
N & 19551 & 19917 & 5927 \\
Parties & 197 & 197 & 52 \\
(Var) Parties & 0.69 & 0.88 & 0.72 \\
\hline
\end{tabular}

Table SI4.2: Bivariate models (logit coefficients) for Jaro-Winkler text search in press releases

\begin{tabular}{lccc}
\hline & Twitter model & Manifesto model & Press model (JW) \\
\hline Intercept & $\mathbf{- 1 . 6 5}(0.06)$ & $\mathbf{- 1 . 8 5}(0.08)$ & $\mathbf{- 1 . 2 4}(0.12)$ \\
Twitter reach & $\mathbf{0 . 8 3}(0.12)$ & & \\
Manifesto mention $(=1)$ & & $\mathbf{0 . 4 9}(0.18)$ & \\
Press release salience & & & $\mathbf{0 . 5 3}(0.24)$ \\
\hline AIC & 36181.86 & 36849.20 & 13279.25 \\
BIC & 36205.50 & 36872.89 & 13299.31 \\
N & 19551 & 19917 & 5927 \\
Parties & 197 & 197 & 52 \\
(Var) Parties & 0.69 & 0.88 & 0.69 \\
\hline
\end{tabular}


Table SI4.3: Press release models (from Table 3 in main text) with Jaro-Winkler text search in press releases

\begin{tabular}{|c|c|c|}
\hline & $\begin{array}{l}\text { Press release salience, } \\
\text { JW (subsample) }\end{array}$ & $\begin{array}{r}\text { All three, JW } \\
\text { (subsample) }\end{array}$ \\
\hline Intercept & $\mathbf{- 0 . 8 4}(0.13)$ & $-0.86(0.11)$ \\
\hline Sex $($ Female $=1)$ & $\mathbf{- 0 . 4 1}(0.04)$ & -0.41 (0.04) \\
\hline Age & $\mathbf{0 . 3 8}(0.04)$ & $\mathbf{0 . 3 8}(0.04)$ \\
\hline Secondary education & $0.22(0.05)$ & $0.22(0.05)$ \\
\hline Tertiary education & $\mathbf{0 . 4 2}(0.06)$ & $\mathbf{0 . 4 2}(0.06)$ \\
\hline EU knowledge & $\mathbf{0 . 3 7}(0.05)$ & $0.38(0.05)$ \\
\hline Interest in politics & $\mathbf{0 . 5 1}(0.05)$ & $\mathbf{0 . 5 1}(0.05)$ \\
\hline Campaign exposure & $\mathbf{0 . 3 0}(0.05)$ & $\mathbf{0 . 3 0}(0.05)$ \\
\hline Political discussion & $0.25(0.05)$ & $0.25(0.05)$ \\
\hline EU position & $0.22(0.04)$ & $0.22(0.04)$ \\
\hline News consumption & $0.40(0.05)$ & $\mathbf{0 . 4 0}(0.05)$ \\
\hline Party of lead candidate & $0.21(0.10)$ & $0.06(0.09)$ \\
\hline Press release salience $(\mathrm{JW})$ & $0.22(0.10)$ & $0.11(0.08)$ \\
\hline Manifesto salience & & $\mathbf{0 . 2 6}(0.09)$ \\
\hline Twitter reach & & $\mathbf{0 . 2 1}(0.07)$ \\
\hline AIC & 10983.16 & 10968.09 \\
\hline $\mathrm{BIC}$ & 11115.15 & 11113.27 \\
\hline $\mathrm{N}$ & 5427 & 5427 \\
\hline Parties & 43 & 43 \\
\hline (Var) Parties & 0.06 & 0.02 \\
\hline
\end{tabular}




\section{Country coefficients from main models}

Table SI4.4: Country coefficients

\begin{tabular}{|c|c|c|c|c|c|c|c|}
\hline & $\begin{array}{l}\text { Baseline } \\
\text { (all) }\end{array}$ & $\begin{array}{c}\text { Twitter } \\
\text { reach (all) }\end{array}$ & $\begin{array}{l}\text { Manifesto } \\
\text { mentions } \\
\text { (all) }\end{array}$ & Both (all) & $\begin{array}{c}\text { Baseline } \\
\text { (subsample) }\end{array}$ & $\begin{array}{c}\text { Press } \\
\text { release } \\
\text { salience } \\
\text { (subsample) }\end{array}$ & $\begin{array}{c}\text { All three } \\
\text { (subsample) }\end{array}$ \\
\hline $\begin{array}{l}\text { Intercept } \\
\text { (Austria) }\end{array}$ & $\mathbf{- 0 . 7 8}(0.16)$ & $\mathbf{- 0 . 7 8}(0.14)$ & $\mathbf{- 0 . 8 5}(0.15)$ & $\mathbf{- 0 . 8 2}(0.14)$ & $\mathbf{- 0 . 8 8}(0.14)$ & $\mathbf{- 0 . 8 4}(0.14)$ & $\mathbf{- 0 . 8 6}(0.11)$ \\
\hline Belgium & $0.32(0.19)$ & $\mathbf{0 . 3 6}(0.17)$ & $\mathbf{0 . 3 8}(0.19)$ & $\mathbf{0 . 3 9}(0.17)$ & & & \\
\hline Bulgaria & $\mathbf{- 1 . 4 1}(0.22)$ & $\mathbf{- 1 . 1 4}(0.20)$ & $\mathbf{- 1 . 3 3}(0.22)$ & -1.11 (0.20) & & & \\
\hline Croatia & $\mathbf{- 1 . 6 8}(0.26)$ & $\mathbf{- 1 . 3 9}(0.23)$ & $\mathbf{- 1 . 6 0}(0.26)$ & $\mathbf{- 1 . 3 6}(0.23)$ & & & \\
\hline Cyprus & $\mathbf{- 1 . 6 6}(0.24)$ & $\mathbf{- 1 . 3 4}(0.22)$ & $\mathbf{- 1 . 5 7}(0.24)$ & $\mathbf{- 1 . 3 1}(0.22)$ & & & \\
\hline Czech R. & $\mathbf{- 2 . 5 5}(0.22)$ & $\mathbf{- 2 . 4 3}(0.19)$ & $\mathbf{- 2 . 6 1}(0.21)$ & $\mathbf{- 2 . 4 7}(0.19)$ & & & \\
\hline Denmark & $\mathbf{- 1 . 8 5}(0.21)$ & -1.73 (0.18) & $\mathbf{- 1 . 7 9}(0.20)$ & $\mathbf{- 1 . 7 0}(0.18)$ & & & \\
\hline Estonia & $\mathbf{- 2 . 7 8}(0.24)$ & $\mathbf{- 2 . 4 0}(0.22)$ & $-2.74(0.24)$ & $\mathbf{- 2 . 4 0}(0.22)$ & & & \\
\hline Finland & -1.11 (0.20) & $\mathbf{- 1 . 0 3}(0.17)$ & $\mathbf{- 1 . 0 4}(0.20)$ & $\mathbf{- 0 . 9 9}(0.17)$ & & & \\
\hline France & $\mathbf{- 1 . 7 9}(0.22)$ & $\mathbf{- 1 . 8 2}(0.20)$ & $\mathbf{- 1 . 8 2}(0.22)$ & $\mathbf{- 1 . 8 3}(0.20)$ & $\mathbf{- 1 . 7 6}(0.20)$ & $\mathbf{- 1 . 7 9}(0.19)$ & $\mathbf{- 1 . 8 6}(0.15)$ \\
\hline Germany & $\mathbf{0 . 4 7}(0.20)$ & $\mathbf{0 . 5 3}(0.17)$ & $\mathbf{0 . 4 3}(0.20)$ & $\mathbf{0 . 5 1}(0.17)$ & $\mathbf{0 . 4 9}(0.16)$ & $\mathbf{0 . 4 8}(0.16)$ & $\mathbf{0 . 4 7}(0.11)$ \\
\hline Greece & $\mathbf{- 1 . 0 3}(0.22)$ & $\mathbf{- 0 . 9 7}(0.19)$ & $\mathbf{- 1 . 0 8}(0.21)$ & $\mathbf{- 1 . 0 0}(0.19)$ & $\mathbf{- 0 . 9 9}(0.18)$ & $\mathbf{- 1 . 0 3}(0.18)$ & $-1.08(0.13)$ \\
\hline Hungary & $\mathbf{- 1 . 9 4}(0.26)$ & $\mathbf{- 1 . 6 5}(0.23)$ & $\mathbf{- 1 . 9 2}(0.26)$ & $\mathbf{- 1 . 6 6}(0.23)$ & & & \\
\hline Ireland & $\mathbf{- 2 . 1 4}(0.23)$ & -1.95 (0.20) & $\mathbf{- 2 . 0 6}(0.22)$ & -1.92(0.20) & & & \\
\hline Italy & $\mathbf{- 1 . 1 0}(0.23)$ & $\mathbf{- 1 . 1 2}(0.20)$ & $\mathbf{- 1 . 0 2}(0.23)$ & $\mathbf{- 1 . 0 8}(0.20)$ & & & \\
\hline Latvia & $\mathbf{- 2 . 0 8}(0.24)$ & $\mathbf{- 1 . 7 7}(0.21)$ & $\mathbf{- 2 . 0 0}(0.23)$ & $\mathbf{- 1 . 7 4}(0.21)$ & & & \\
\hline Lithuania & $-\mathbf{2 . 3 9}(0.23)$ & $\mathbf{- 1 . 9 8}(0.21)$ & $-2.36(0.23)$ & $\mathbf{- 1 . 9 8}(0.21)$ & & & \\
\hline Lux. & $\mathbf{0 . 5 5}(0.26)$ & $\mathbf{0 . 5 9}(0.23)$ & $\mathbf{0 . 5 5}(0.26)$ & $\mathbf{0 . 5 8}(0.23)$ & & & \\
\hline Poland & $\mathbf{- 2 . 2 9}(0.23)$ & $\mathbf{- 2 . 0 8}(0.21)$ & $\mathbf{- 2 . 2 1}(0.23)$ & $\mathbf{- 2 . 0 5}(0.21)$ & & & \\
\hline Portugal & $\mathbf{- 1 . 6 7}(0.28)$ & $\mathbf{- 1 . 4 6}(0.24)$ & $\mathbf{- 1 . 5 9}(0.27)$ & $\mathbf{- 1 . 4 3}(0.24)$ & $\mathbf{- 1 . 6 2}(0.22)$ & $\mathbf{- 1 . 6 0}(0.21)$ & -1.35 (0.16) \\
\hline Romania & $\mathbf{- 2 . 0 1}(0.23)$ & $\mathbf{- 1 . 8 1}(0.21)$ & $\mathbf{- 2 . 0 4}(0.23)$ & $\mathbf{- 1 . 8 4}(0.20)$ & & & \\
\hline Slovakia & $\mathbf{- 2 . 4 4}(0.23)$ & $\mathbf{- 2 . 0 6}(0.21)$ & $\mathbf{- 2 . 4 1}(0.23)$ & $\mathbf{- 2 . 0 6}(0.21)$ & & & \\
\hline Slovenia & $\mathbf{- 1 . 1 8}(0.23)$ & $\mathbf{- 0 . 9 8}(0.20)$ & $\mathbf{- 1 . 0 8}(0.23)$ & $\mathbf{- 0 . 9 3}(0.20)$ & & & \\
\hline Spain & $\mathbf{- 1 . 8 9}(0.23)$ & $\mathbf{- 1 . 8 1}(0.20)$ & $\mathbf{- 1 . 9 1}(0.22)$ & -1.82 (0.20) & & & \\
\hline Sweden & $\mathbf{- 1 . 7 8}(0.19)$ & -1.65 (0.17) & -1.69(0.19) & $\mathbf{- 1 . 6 1}(0.17)$ & & & \\
\hline Netherlands & $\mathbf{- 0 . 9 0}(0.19)$ & $\mathbf{- 0 . 9 1}(0.17)$ & $\mathbf{- 0 . 8 7}(0.19)$ & $\mathbf{- 0 . 8 9}(0.17)$ & $\mathbf{- 0 . 8 9}(0.15)$ & $\mathbf{- 0 . 9 5}(0.15)$ & $\mathbf{- 0 . 8 8}(0.11)$ \\
\hline UK & $\mathbf{- 2 . 4 4}(0.22)$ & $-2.34(0.20)$ & $-\mathbf{2 . 3 6}(0.22)$ & $\mathbf{- 2 . 3 0}(0.19)$ & $\mathbf{- 2 . 2 5}(0.19)$ & $-2.22(0.19)$ & $-2.13(0.14)$ \\
\hline
\end{tabular}


Table SI4.5: Robustness and Placebo test models

\begin{tabular}{|c|c|c|c|c|c|}
\hline & $\begin{array}{l}\text { Partisans } \\
\text { only }\end{array}$ & $\begin{array}{l}\text { EU } \\
\text { knowledge }\end{array}$ & $\begin{array}{l}\text { Proportion } \\
\text { candidates }\end{array}$ & $\begin{array}{l}\text { Proportion } \\
\text { Tweets }\end{array}$ & $\begin{array}{l}\text { 3-level } \\
\text { model }\end{array}$ \\
\hline Intercept & $\mathbf{- 0 . 6 8}(0.15)$ & $1.85(0.11)$ & $\mathbf{- 0 . 9 0}(0.14)$ & $\mathbf{- 0 . 8 4}(0.15)$ & $\mathbf{- 2 . 1 4}(0.17)$ \\
\hline Sex $($ Female $=1)$ & $\mathbf{- 0 . 3 9}(0.03)$ & $\mathbf{- 0 . 2 1}(0.03)$ & $\mathbf{- 0 . 4 1}(0.03)$ & $\mathbf{- 0 . 4 1}(0.03)$ & $\mathbf{- 0 . 4 1}(0.03)$ \\
\hline Age & $\mathbf{0 . 2 8}(0.03)$ & $\mathbf{0 . 2 6}(0.03)$ & $\mathbf{0 . 3 3}(0.03)$ & $\mathbf{0 . 3 3}(0.03)$ & $\mathbf{0 . 3 3}(0.03)$ \\
\hline Secondary education & $\mathbf{0 . 2 4}(0.04)$ & $0.06(0.04)$ & $\mathbf{0 . 2 4}(0.04)$ & $\mathbf{0 . 2 4}(0.04)$ & $\mathbf{0 . 2 4}(0.04)$ \\
\hline Tertiary education & $\mathbf{0 . 4 1}(0.04)$ & $\mathbf{0 . 4 2}(0.04)$ & $\mathbf{0 . 4 2}(0.04)$ & $\mathbf{0 . 4 2}(0.04)$ & $\mathbf{0 . 4 2}(0.04)$ \\
\hline EU knowledge & $\mathbf{0 . 3 2}(0.03)$ & & $\mathbf{0 . 3 5}(0.03)$ & $\mathbf{0 . 3 5}(0.03)$ & $0.35(0.03)$ \\
\hline Interest in politics & $\mathbf{0 . 5 6}(0.04)$ & $\mathbf{0 . 2 8}(0.03)$ & $\mathbf{0 . 5 7}(0.03)$ & $\mathbf{0 . 5 7}(0.03)$ & $\mathbf{0 . 5 7}(0.03)$ \\
\hline Campaign exposure & $\mathbf{0 . 1 1}(0.04)$ & $0.03(0.03)$ & $\mathbf{0 . 1 3}(0.03)$ & $\mathbf{0 . 1 3}(0.03)$ & $\mathbf{0 . 1 3}(0.03)$ \\
\hline Political discussion & $\mathbf{0 . 2 7}(0.03)$ & $\mathbf{0 . 1 9}(0.03)$ & $\mathbf{0 . 2 9}(0.03)$ & $\mathbf{0 . 2 9}(0.03)$ & $\mathbf{0 . 2 9}(0.03)$ \\
\hline EU position & $\mathbf{0 . 1 9}(0.03)$ & $\mathbf{- 0 . 1 4}(0.03)$ & $\mathbf{0 . 2 0}(0.03)$ & $\mathbf{0 . 2 0}(0.03)$ & $\mathbf{0 . 2 0}(0.03)$ \\
\hline News consumption & $\mathbf{0 . 4 3}(0.03)$ & $\mathbf{0 . 1 8}(0.03)$ & $\mathbf{0 . 4 2}(0.03)$ & $\mathbf{0 . 4 2}(0.03)$ & $0.42(0.03)$ \\
\hline $\begin{array}{l}\text { Party of lead } \\
\text { candidate }\end{array}$ & $0.07(0.06)$ & $-0.03(0.05)$ & $\mathbf{0 . 2 8}(0.06)$ & $\mathbf{0 . 3 0}(0.06)$ & $\mathbf{0 . 1 6}(0.07)$ \\
\hline Manifesto salience & $0.09(0.08)$ & $0.03(0.06)$ & $\mathbf{0 . 1 7}(0.09)$ & $\mathbf{0 . 2 5}(0.09)$ & $0.13(0.09)$ \\
\hline Twitter reach & $\mathbf{0 . 2 8}(0.07)$ & $0.04(0.05)$ & & & $\mathbf{0 . 4 3}(0.07)$ \\
\hline $\begin{array}{l}\text { Twitter: proportion of } \\
\text { cands. }\end{array}$ & & & $\mathbf{0 . 3 7}(0.07)$ & & \\
\hline $\begin{array}{l}\text { Twitter: proportion of } \\
\text { tweets }\end{array}$ & & & & $\mathbf{0 . 2 2}(0.07)$ & \\
\hline$\overline{\mathrm{AIC}}$ & 22005.36 & 27996.14 & 31782.76 & 31800.16 & 31844.88 \\
\hline $\mathrm{BIC}$ & 22307.89 & 28310.13 & 32104.61 & 32122.00 & 31970.48 \\
\hline $\mathrm{N}$ & 11834 & 18957 & 18957 & 18957 & 18957 \\
\hline Parties & 149 & 176 & 176 & 176 & \\
\hline (Var) Parties & 0.06 & 0.02 & 0.08 & 0.10 & \\
\hline Parties & & & & & 176 \\
\hline Countries & & & & & 27 \\
\hline $\begin{array}{l}\text { (Var) Parties in } \\
\text { country }\end{array}$ & & & & & 0.11 \\
\hline (Var) Country & & & & & 0.67 \\
\hline
\end{tabular}


Table SI4.6: Age split models

\begin{tabular}{lcc}
\hline & Age group, & Age group, \\
& 35-year split & 25-year split \\
\hline Intercept & $\mathbf{- 0 . 6 8}(0.14)$ & $\mathbf{- 0 . 7 2}(0.14)$ \\
Age $(<=35)$ & $\mathbf{- 0 . 3 3}(0.05)$ & \\
Sex $($ Female $=1)$ & $\mathbf{- 0 . 4 2}(0.03)$ & $\mathbf{- 0 . 4 2}(0.03)$ \\
Secondary education & $\mathbf{0 . 1 9}(0.04)$ & $\mathbf{0 . 1 8}(0.04)$ \\
Tertiary education & $\mathbf{0 . 3 7}(0.04)$ & $\mathbf{0 . 3 5}(0.04)$ \\
EU knowledge & $\mathbf{0 . 3 5}(0.03)$ & $\mathbf{0 . 3 6}(0.03)$ \\
Interest in politics & $\mathbf{0 . 5 9}(0.03)$ & $\mathbf{0 . 6 1}(0.03)$ \\
Campaign exposure & $\mathbf{0 . 1 3}(0.03)$ & $\mathbf{0 . 1 2}(0.03)$ \\
Political discussion & $\mathbf{0 . 3 0}(0.03)$ & $\mathbf{0 . 3 0}(0.03)$ \\
EU position & $\mathbf{0 . 2 0}(0.03)$ & $\mathbf{0 . 1 9}(0.03)$ \\
News consumption & $\mathbf{0 . 3 9}(0.03)$ & $\mathbf{0 . 3 9}(0.03)$ \\
Party of lead candidate & $\mathbf{0 . 1 6}(0.06)$ & $\mathbf{0 . 1 6}(0.06)$ \\
Manifesto salience & $0.10(0.08)$ & $0.14(0.09)$ \\
Twitter reach & $\mathbf{0 . 3 9}(0.07)$ & $\mathbf{0 . 4 1}(0.07)$ \\
Age $(<=35):$ Twitter reach & $-0.04(0.09)$ & \\
Age $(<=25)$ & & $\mathbf{0 . 3 0}(0.08)$ \\
Age $(<=25):$ Twitter reach & & $0.04(0.13)$ \\
\hline AIC & 31788.27 & 31660.25 \\
BIC & 32133.64 & 18854 \\
N & 18948 & 168 \\
Parties & 174 & 0.08 \\
(Var) Parties (intercept) & 0.07 & \\
(Var) Parties (Age $<=35)$ & 0.12 & 0.26 \\
(Cov) Intercept $($ Age $<=35)$ & 0.02 & -0.03 \\
(Var) Parties (Age $<=25)$ & & \\
(Cov) Intercept $($ Age $<=25)$ & &
\end{tabular}




\section{Additional robustness checks}

In Figures SI4.2 and SI4.3 we report the coefficients of the party communication measures from the final models in the main text in a setup where we drop a country for each iteration. Excluding one country and re-fitting the model shows that our results are not driven by any specific country.

Figure SI4.2: Systematic sub-sample analysis (1)

Robustness test: final models with one country dropped Twitter outreach

Manifesto salience
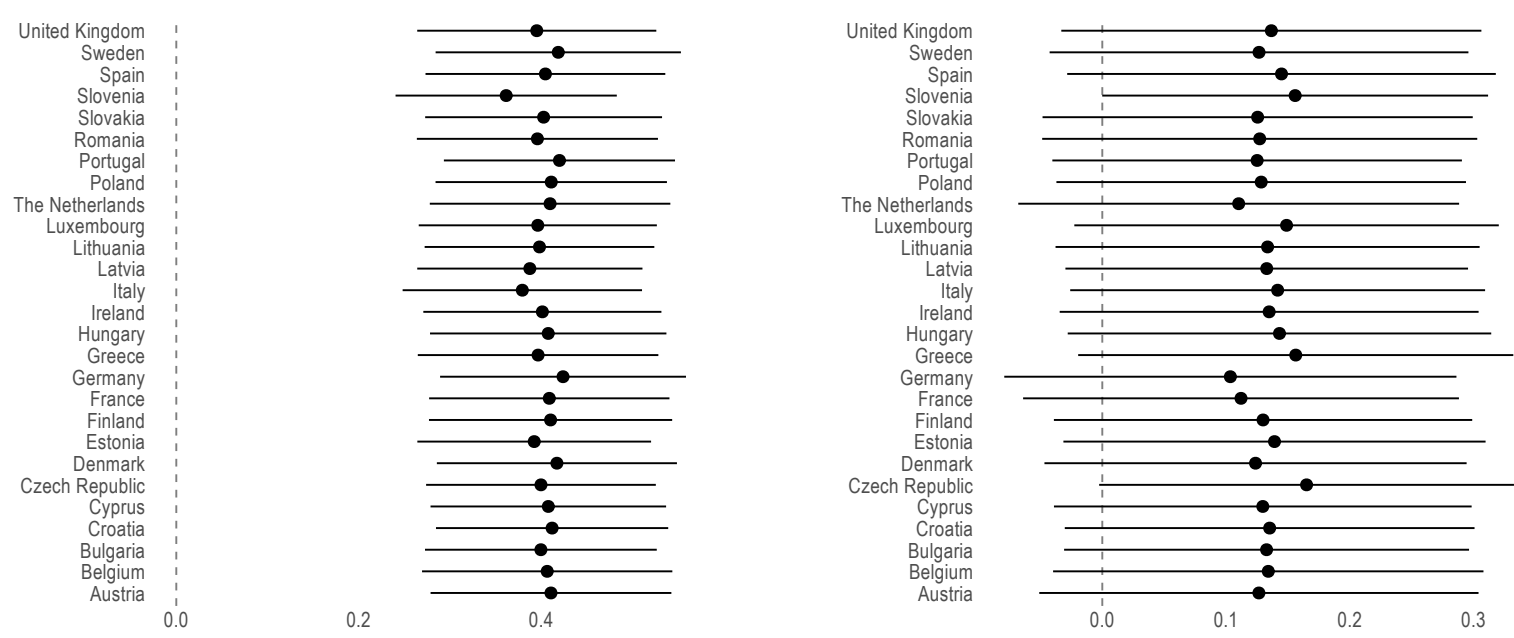

Logit coefficients. Country name on $y$-axis reflects the country that was excluded.

Figure SI4.3: Systematic sub-sample analysis (2)
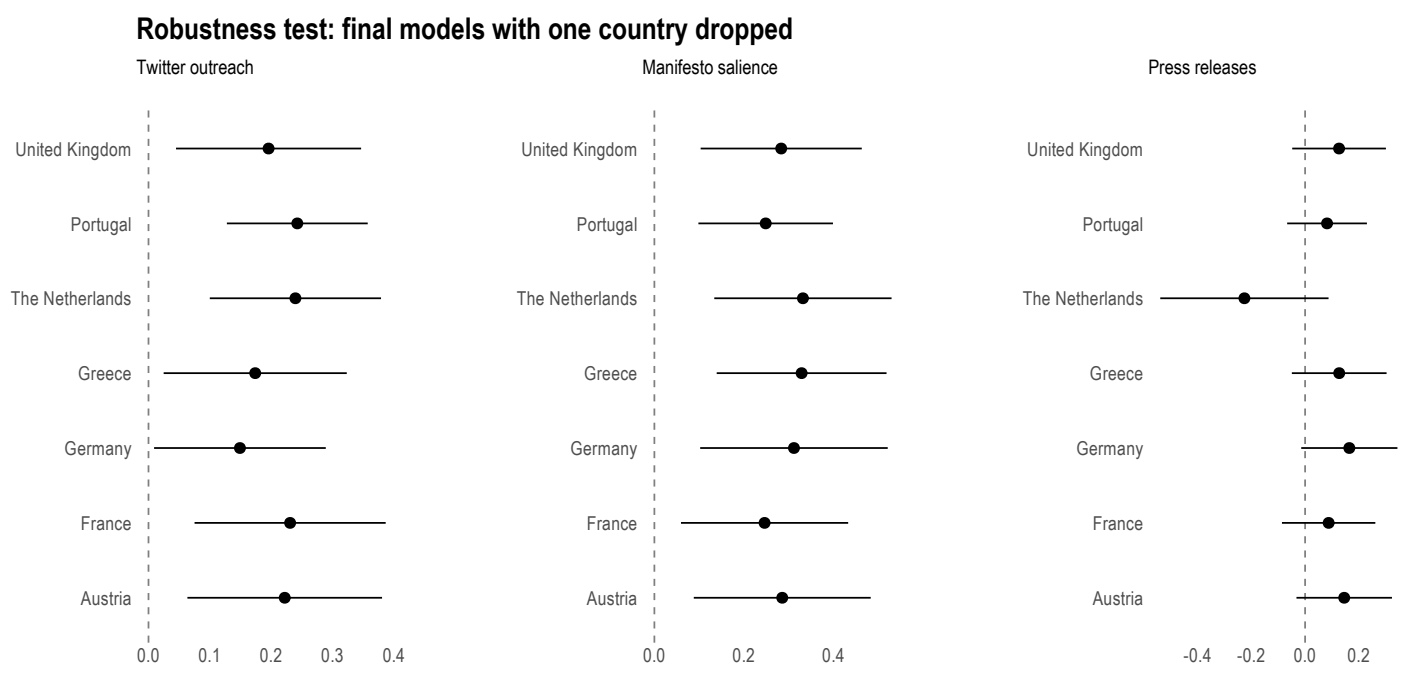

Logit coefficients. Country name on $y$-xis reflects the country that was excluded 
As introduced in SI 3, a final alternative Twitter outreach measure (not included in previous robustness tests) is one where we simply sum all the potential followers reached by Spitzenkandidaten tweets (summed each Tweet following for each party) and divide it by the number of votes the parties received in the 2014 EP elections. After the same mean centering and two-standard deviation division rescaling, we report in the Table below results from the final models for both samples (full sample and where press-releases are available).

Table SI4.7: Twitter models

\begin{tabular}{lcc}
\hline & Both (all) & All three (subsample) \\
\hline Intercept & $\mathbf{- 0 . 8 3}(0.14)$ & $\mathbf{- 0 . 8 5}(0.11)$ \\
Sex (Female =1) & $\mathbf{- 0 . 4 1}(0.03)$ & $\mathbf{- 0 . 4 1}(0.04)$ \\
Age & $\mathbf{0 . 3 3}(0.03)$ & $\mathbf{0 . 3 8}(0.04)$ \\
Secondary education & $\mathbf{0 . 2 4}(0.04)$ & $\mathbf{0 . 2 2}(0.05)$ \\
Tertiary education & $\mathbf{0 . 4 2}(0.04)$ & $\mathbf{0 . 4 2}(0.06)$ \\
EU knowledge & $\mathbf{0 . 3 5}(0.03)$ & $\mathbf{0 . 3 8}(0.05)$ \\
Interest in politics & $\mathbf{0 . 5 7}(0.03)$ & $\mathbf{0 . 5 1}(0.05)$ \\
Campaign exposure & $\mathbf{0 . 1 3}(0.03)$ & $\mathbf{0 . 3 0}(0.05)$ \\
Political discussion & $\mathbf{0 . 2 9}(0.03)$ & $\mathbf{0 . 2 5}(0.05)$ \\
EU position & $\mathbf{0 . 2 0}(0.03)$ & $\mathbf{0 . 2 2}(0.04)$ \\
News consumption & $\mathbf{0 . 4 2}(0.03)$ & $\mathbf{0 . 4 0}(0.05)$ \\
Party of lead candidate & $\mathbf{0 . 1 8}(0.06)$ & $0.08(0.09)$ \\
Manifesto salience & $0.14(0.08)$ & $\mathbf{0 . 2 6}(0.09)$ \\
Twitter reach/votes & $\mathbf{0 . 4 3}(0.07)$ & $\mathbf{0 . 2 1}(0.07)$ \\
Press release salience & & $0.09(0.08)$ \\
\hline AIC & 31773.54 & 10967.57 \\
BIC & 32095.39 & 11112.75 \\
N & 18957 & 5427 \\
Parties & 176 & 43 \\
(Var) Parties & 0.08 & 0.02 \\
\hline
\end{tabular}

